\title{
Extracellular Vesicles in Premature Aging and Diseases in Adulthood Due to Developmental Exposures
}

\author{
Marisa R. Pinson, Dae D. Chung, Amy M. Adams, Chiara Scopice, Elizabeth A. Payne, Monisha \\ Sivakumar, Rajesh C. Miranda* \\ Department of Neuroscience and Experimental Therapeutics, Texas A\&M University Health Science Center, \\ Bryan, TX 77807, USA
}

[Received January 11, 2021; Revised March 22, 2021; Accepted March 22, 2021]

\begin{abstract}
The developmental origins of health and disease (DOHaD) is a paradigm that links prenatal and early life exposures that occur during crucial periods of development to health outcome and risk of disease later in life. Maternal exposures to stress, some psychoactive drugs and alcohol, and environmental chemicals, among others, may result in functional changes in developing fetal tissues, creating a predisposition for disease in the individual as they age. Extracellular vesicles (EVs) may be mediators of both the immediate effects of exposure during development and early childhood as well as the long-term consequences of exposure that lead to increased risk and disease severity later in life. Given the prevalence of diseases with developmental origins, such as cardiovascular disease, neurodegenerative disorders, osteoporosis, metabolic dysfunction, and cancer, it is important to identify persistent mediators of disease risk. In this review, we take this approach, viewing diseases typically associated with aging in light of early life exposures and discuss the potential role of EVs as mediators of lasting consequences.
\end{abstract}

Key words: extracellular vesicles, developmental origin of health and disease, prenatal exposure, early childhood adversity, miRNA

\section{Developmental Origins of Health and Disease}

The epidemiologist, David Barker, first presented evidence in the 1980s and 1990s which suggested that maternal/fetal undernutrition at various stages of pregnancy could alter the susceptibility of offspring to metabolic and cardiovascular disease in later life [1,2]. These data suggested that fetal mis-programming during critical developmental periods could have long-term adverse consequences for adult health. Over time, this fetal programming hypothesis evolved into a generalized paradigm, termed the Developmental Origins of Health and Disease $(\mathrm{DOHaD})$, and a significant area for research focused on identifying mechanisms that mediate the effects of environmental perturbations in early development on health outcomes and disease predisposition in later life (Fig. 1). This area of study has contributed towards the development of a more expansive framework, wherein insults in utero or in early life such as undernutrition [1-3], stressors [4], and teratogens, such as alcohol [5-7], may lead to epigenetic modifications with consequences lasting into adulthood. The evolution of the $\mathrm{DOHaD}$ framework is coincident with the evolution of a related 'two-hit' hypothesis which was originally developed by the cancer biologist Alfred Knudson [8], to explain that retinoblastoma, an ocular cancer in young children, was due to the accumulation of two mutational events or two "hits". This theory that two or more insults

*Correspondence should be addressed to: Dr. Rajesh C. Miranda, Department of Neuroscience and Experimental Therapeutics, Texas A\&M University Health Science Center, Bryan, TX 77807, USA. Email: rmiranda@ tamu.edu.

Copyright: () 2021 Pinson MR et al. This is an open-access article distributed under the terms of the Creative Commons Attribution License, which permits unrestricted use, distribution, and reproduction in any medium, provided the original author and source are credited. 
that occur early in development may have synergistic repercussions later in life can be applied to the DOHaD hypothesis. For instance, hypertension [3, 9-11], stroke $[12,13]$, neurodegenerative disorders [14,15], osteoporosis [16,17], sleep disorders [18-25], organ fibrosis [26-28], metabolic dysfunction [29-33] and cancer $[34,35]$ are all diseases that have an onset in later life, and could be triggered by temporally proximate experiences, but the increased risk for these diseases could have a developmental origin. Furthermore, several disorders better appreciated for their developmental origins, such as Fetal Alcohol Spectrum Disorders (FASDs), are associated with premature aging [5], suggesting that early developmental experiences can influence the onset of diseases that are typically considered aging-related. Here we will briefly describe several examples on how prenatal and early life exposures and stressors have been shown to contribute to impaired health and diseases in later life.

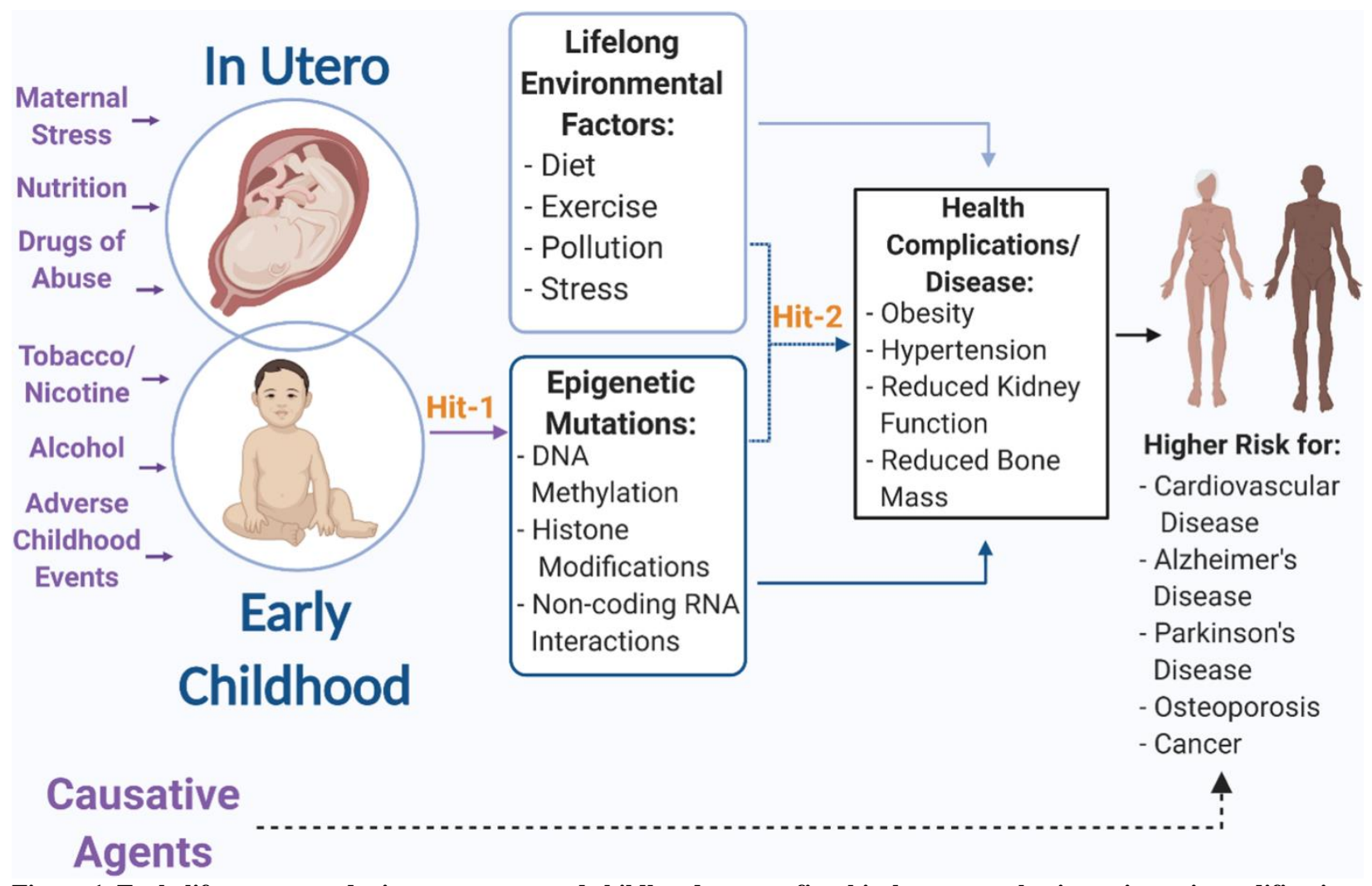

Figure 1. Early life exposures during pregnancy and childhood act as a first hit that creates lasting epigenetic modifications that increase risk of health complications and diseases later in life. Additionally, this first hit makes the individual more susceptible to a second environmental hit during life that may further increase risk of disease or increase likelihood of adverse events. (Created with BioRender.com.)

\subsection{Prenatal alcohol exposure as an initial hit}

Fetal Alcohol Spectrum Disorders (FASDs) is a term coined to describe a spectrum of developmental abnormalities that are initiated by prenatal alcohol exposure (PAE) and have the potential to affect multiple organ systems [36, 37]. The most visibly severe end of the spectrum is Fetal Alcohol Syndrome (FAS), which is characterized by, but is not limited to, developmental delays and cranio-facial abnormalities [36]. The estimate for school-aged children affected by FASD is $1.1-5 \%$ in the United States [38]. However, in two separate statewide studies in the US, the prevalence of PAE was demonstrated to be higher than previous estimates [39, 40]. With over $50 \%$ of pregnancies being unplanned [41], and $22.5 \%$ of women consuming alcohol within the first month of pregnancy [41], PAE in an unintentional pregnancy is a likely possibility. The effects of PAE can be viewed with a two-hit hypothesis perspective. The altered programming of genes due to alcohol exposure is the result of the first "hit", which in turn has been shown to predispose individuals with FASD for negative health outcomes such as cardiovascular disease [42-45], compromised immune system [46-51], and diabetes and 
metabolic disorders [52-55]. Stressors or environmental factors in later life can subsequently interact with the ethanol-induced genetic modifications, acting as a second "hit" to tip the balance favoring development of early onset systemic diseases. For example, one study reported that both single and repeated maternal ethanol exposures resulted in redistribution of fetal blood flow to support pertinent organs such as the brain [56]. This 'brain sparing' phenomena is associated with disproportionate fetal growth $[57,58]$, and may impede the development of other organs. For example, the number of renal nephrons is permanently reduced by acute alcohol exposure in early development [59]. This reduction in nephron number has also been observed in patients with primary hypertension, suggesting that the reduction of nephrons from PAE may result in hypertension in later life [60] which may in turn serve as a proximate risk factor for cerebrovascular stroke [61]. Previous research shows that even a single episode of alcohol exposure can result in modifications to chromatin structure, and can induce birth defects [6]. Ethanol interferes with neural stem cell formation and maintenance, which can directly affect neural development [62-64]. Maternal ethanol consumption causes a depletion of neural stem cells, leaving the maturing neural cells vulnerable to genetic damage and resulting in abnormal neural maturation [62-64]. The loss of neural stem cells has been implicated in the etiology of neurodegenerative diseases like Alzheimer's disease and therapies focused on neural regeneration are a promising experimental approach to minimizing the effects of neurodegeneration [65]. However, the early loss of neural stem cells may pre-dispose individuals with FASD towards an increased risk for dementia. Additionally, PAE has been linked to deficits in hippocampal plasticity as well as impaired memory [66, 67], impacting a brain region already closely associated with Alzheimer's disease, again suggesting increased risk for dementia [68].

\subsection{Prenatal nicotine exposure as an initial hit}

In the United States, approximately 1 in 14 women reported smoking during pregnancy [69]. Smoking during pregnancy has detrimental effects such as low birthweight, stillbirth, and other birth defects [69]. In rats, nicotine has been demonstrated to induce abnormal brain maturation through the partial inhibition of DNA synthesis in the fetal brain and the elevated presence of ornithine decarboxylase, a biomarker related to cellular maturation [70-72]. Although maternal smoking is associated with adverse outcomes such as learning impairment [70, 73], further studies are necessary to establish the long-term neurological effects of nicotine, specifically. Intrauterine or early life nicotine exposure may contribute towards risk of type 2 diabetes [74]. It has been demonstrated that nicotine exposure in utero and in neonate rats leads to a disruption in pancreatic development as well as a reduced quantity and impaired function of beta cells $[74,75]$. The elevated levels of beta cell apoptosis in rats as well as changes in glucose homeostasis are associated with type- 2 diabetes [74, 75].

\subsection{Maternal stress and early childhood adversity as an initial hit}

A wide variety of factors and diseases, such as depression and preeclampsia, can be considered maternal stressors. Maternal stressors can have consequential effects on the offspring's long-term health by increasing the risk or prevalence of chronic disease. In the third trimester, it is estimated that approximately $12 \%$ of pregnant women experience depression [76]. One study focused on the impact of maternal depression on alterations in DNA methylation in $\mathrm{T}$ lymphocytes and the adult hippocampus [77]. This study reported that, at birth, there was predominant chromatin hypomethylation in $T$ lymphocytes isolated from umbilical cord blood [77]. Additionally, this study identified changes in DNA methylation in the hippocampus of adult offspring[77]. This suggests that maternal psychological states may result in life-long and multi-system effects in offspring. Maternal preeclampsia has recently been tied to an increased risk for the later development of cardiovascular and neurological diseases in offspring [78]. In the Helsinki Cohort, offspring born to mothers who developed preeclampsia or gestational hypertension during pregnancy exhibited an increased risk for stroke later in life $[78,79]$. Preeclampsia was associated with reduced head circumference [79], whereas gestational hypertension was associated with reduced birth weights and exemplified characteristics pertaining to the brain sparing' phenomena [79]. Adverse events in early childhood, such as trauma, can increase the likelihood of developing cardiovascular disease as well as type 2 diabetes [80]. Another study using the Helsinki cohort, analyzed the effects of early childhood separation from parents during World War II, when a large number of children were evacuated to Sweden and Denmark [80]. Children who were separated from their parents were twice as likely to be diagnosed with cardiovascular disease in comparison to those who were not [80]. The Adverse Childhood Experiences Study supported a relationship between health risk associated with childhood physical, emotional/sexual abuse, neglect, and household dysfunction [81]. Children were at a higher risk of developing disease in later life when they were exposed to multiple categories of adverse events (e.g. psychological, physical, sexual, household dysfunction) [81]. These exposures were associated in adulthood with 
an increased incidence of diseases such as ischemic heart disease, cancer, skeletal fractures, and liver disease [81, 82]. The mechanisms that link early adversity to adultonset disease are unclear. Here, we examine the potential influence of a novel endocrine signal, mediated by a class of circulating, membrane-enclosed structures termed extracellular vesicles.

\section{Extracellular Vesicles}

Membrane-bound extracellular vesicles (EVs) are released from all cell types, contain content derived from the host cell, and have the ability to transfer that content to recipient cells and tissues [83, 84]. EVs are often subcategorized into two classes, exosomes and ectosomes $[85,86]$. Ectosomes are also frequently referred to as shedding vesicles, microvesicles, exosome-like vesicles, nanoparticles, microparticles, and oncosomes [87]. EVs are heterogenous, but potentially functional structures that are carriers of various biomolecules, dependent on the content of their cells-of-origin. They can contain membrane-bound and free proteins including enzymes, whole or fragmented RNAs (mRNA, miRNA, IncRNA, etc.), DNA, and lipids [88-91]. EVs can be taken up by recipient cells through endocytosis or fusion directly with the cell membrane, or function through interactions between EV-bound ligands and cell membrane receptors [92]. Through these interactions, whether transferring its cargo or activating cell receptors, EVs represent a novel endocrine or paracrine mode for intercellular communication [93-96]. Because EVs may mediate both homotypic and heterotypic cell-to-cell communication and even potentially exchange information between distant tissues, they are well-positioned to play both protective and pathogenic roles in normal physiology and in disease states.

\section{Potential role of EVs as mediators and perpetuators of prenatal and early life insult in diseases of aging}

As mentioned earlier, epigenetic modifications of DNA and associated histones as well as alterations in regulatory networks of non-protein-coding RNAs constitute a critical biological substrate in the DOHaD hypothesis (Fig. 1), that transduce the effects of early life experience into both health and disease risks over a lifetime. MicroRNAs (miRNA), a type of small noncoding RNA, that regulate networks of protein-coding genes by translationinhibition $[97,98]$ have been localized to EVs. Moreover, miRNAs isolated from circulation and cerebrospinal fluid have been identified as biomarkers for specific diseases and illnesses and may be a potential therapeutic target [99104]. Cells and tissues from which EVs originate have the potential to control protein translation and function in distal tissues, by transferring RNA and protein cargo in EVs to recipient cells. Consequently, any alteration to the cargo carried by EVs following exposure to an environmental stressor may have immediate and widespread consequences for organ development resulting in a permanent change in developmental trajectory and facilitating an accumulation of damage as an individual ages that later manifests as diseases such as atherosclerosis, dementia, or osteoporosis[105-108]. EVs may have a role in explaining the mechanistic underpinnings of the DOHaD theory and evidence to support this will be discussed here. Currently there is a paucity of research that focuses on the specific question of how EVs mediate progression of diseases of developmental origins. However, in this review, we assess the body of research that exists and reveal connections that supports EVs as mediators, hopefully guiding hypotheses for future work. We have chosen to focus on those diseases for which developmental exposures have been shown to contribute to increased risk of developing.

\subsection{EVs in the Developmental Origin of Adult-onset Cardiac and Skeletal Disease}

\section{1.i Cardiovascular disease}

In 1990, environmental conditions in utero were first documented to have an effect on blood pressure and hypertension in adults [9]. The perturbation-induced discrepancy between fetal and placental size was thought to contribute towards this increased risk for cardiovascular disease [9]. Since these early studies, a number of subsequent studies have linked fetal undernutrition to cardiovascular disease (CVD) [1, 2]. Low birth-weight poses a greater risk for coronary heart disease and stroke in later health, in part due to the reduced rates of fetal growth [13, 109]. The 'brainsparing' phenomena which occurs due to the reduced rates of fetal growth cause a redistribution of blood to favor circulation to the brain. The resulting decrease in systemic blood circulation in arteries may hinder their elasticity[13, 110], and this sequence of events is hypothesized to lead to hypertension and increased susceptibility for hemorrhagic stroke $[13,110]$. Additionally, the altered blood circulation affects other organs such as the liver which faces an elevated concentration of plasma fibrinogen $[13,111]$, a factor associated with thrombotic stroke $[13,112]$.

One developmental risk factor for CVD later in life is congenital heart disease (CHD), which is one of the most common congenital malformations diagnosed in newborns with a prevalence of $7.5 \%$ of live births worldwide [113]. As diagnostics and surgical interventions have improved for CHD, patients are 
surviving to an older age [114]. In fact, the majority of patients with CHD seen in clinical practice are adults, and they will likely continue to represent the largest proportion of patients requiring life-long medical care $[115,116]$. This is because even after surgery in childhood to fix congenital defects, adult CHD patients are at increased rate of CVD risk factors (eg. obesity and hypertension) [117-119] and also in general have an increased risk of CVD (eg. stroke and myocardial infarction) [117, 120-124]. Growing evidence suggests that miRNAs packaged in EVs may contribute to the development of malformations in CHD. A number of studies have identified significantly different levels of circulating miRNAs (miR-34a, miR-142-5p, miR-1275, miR-3664-3p, and miR-4666a-3p) in pregnant women carrying a fetus with CHD compared to women carrying a fetus without CHD [125-127]. Furthermore, bioinformatics analysis has identified these miRNAs as being involved in the regulation of fetal heart development [126-129]. Additionally, prenatal exposure to teratogens, such as alcohol and smoking, may further increase the risk of congenital heart malformations with subsequent lifelong consequences. For example, miR-17$1-3 p$ is increased in EVs from neural stem cells of fetal mice after exposure to ethanol [64] and miR-20a-5p is elevated in EVs isolated from smokers [130]. Both of these miRNAs play a key part in cardiogenesis by participating in the differentiation of progenitor cells in heart muscle. Elevation in their expression is documented to inhibit expression of crucial cardiac progenitor genes like Islet-1 (IslI) and T-box transcription factor 1 (Tbxl), resulting in CHD [131].

Another means by which prenatal and early life exposures may contribute to CVD in adulthood is by increasing the predisposition for additional contributory risk factors, such as obesity, insulin resistance, hypertension, abnormal cholesterol, and an increased risk for clotting [55, 132-135]. For example, impaired glucose homeostasis as well as dyslipidemia has been identified in adult animals prenatally exposed to ethanol [55]. Additionally, there is an increased risk of hypertension and obesity in children prenatally exposed to smoking[132], and secondhand smoking in childhood is also associated with subsequent obesity, dyslipidemia, and insulin resistance [133]. Similar outcomes have been attributed to adverse childhood events and maternal stress during pregnancy $[134,135]$.

This observed phenomenon of fetal and early childhood programming of CVD may be mediated by EVs. For example, cocaine increases release of miR-130a by EVs from human monocyte-derived macrophages and mediates increased smooth muscle proliferation, resulting in pulmonary hypertension [136]. Postnatal oxycodone exposure may also impact vascular smooth muscle cell function by decreasing miR-26a in EVs [137], which can induce a more contractile phenotype in smooth muscle cells [138]. Early exposures like these may predispose an individual to hypertension, by persistently impairing vascular smooth muscle cell function.

An individual may also be primed for dyslipidemia by early life experiences. For instance, ethanol exposure increases miR-145 expression in the fetal mouse brain [139] while oxycodone exposure in utero increases miR$128-1-5 p$ and postnatally elevates miR-451-5p in brainderived EVs from rats [137]. Both miR-145-5p and miR451a are elevated in EVs derived from senescent platelets obtained from human donors and are identified as being associated with lipid metabolism and vascular disease and inflammation [140]. MiR-128 is enriched in EVs from macrophages stimulated by oxLDL to be pro-atherogenic [141] and is also associated with inflammatory and lipid homeostasis pathways [142]. This means that prenatal and postnatal exposures may promote dyslipidemia inducing EVs from a young age, allowing for accumulation of damage over a longer period of time and increasing risk in an individual.

Additional factors may contribute to this earlier damage to the vasculature and accumulation of atherosclerotic lesions later in life. Ethanol use increases miR-155 [143], which mediates destruction of tight junctions and endothelial barrier via EV transfer [144], potentially impacting fetal vascular development and having lifelong consequences. Smoking decreases EV miR-133a [130], a miRNA that has proven beneficial post hypoxic injuries (eg. myocardial infarction) [145] and its downregulation is associated with development of atherosclerosis and arterial calcification [146], meaning a child exposed in utero or via secondhand smoking may suffer from increased risk of atherosclerosis.

Altogether, these first "hits" may ultimately contribute not only to the increased risk for a second "hit", but also to worse outcomes after a second "hit." For example, both miR-21 and miR-150 have been shown to promote cellular recovery post-vascular injury via EV transfer [145, 147, 148] and both have been shown to be suppressed by ethanol and smoking, respectively, suggesting that early life exposures have the ability to not only increase the risk for disease in adulthood, but to also worsen the prognosis that results from a secondary insult. This means that even if the effects of prenatal and postnatal exposures are not immediately recognizable, a second "hit" may uncover an underlying condition that worsens recovery.

\section{1.ii Osteoporosis and Osteoarthritis}

Osteoporosis and osteoarthritis are characterized by tissue remodeling resulting in net loss of bone density and 
cartilage, respectively. The resulting fractures and debilitating pain decrease mobility and quality of life. Bone and cartilage remodeling occurs through continuous resorption and deposition. This remodeling is controlled by growth factors, hormones, and other regulatory molecules.

During development, EVs within amniotic fluid are rich with growth factors that support angiogenesis [149] and chondrogenesis [150]. In fact, amniotic EVs, upon injection into monoiodoacetate-induced arthritic knee joints in vivo restore lost cartilage [150]. Furthermore, EV TGF-beta concentration was significantly positively correlated with cartilage restoration [150]. This means that any perturbations in EV cargo or trafficking that may result from in utero exposure has the potential to have negative consequences on proper bone and cartilage formation and integrity, creating a predisposition for osteoporosis and osteoarthritis earlier in life. For example, both PAE and prenatal tobacco smoke (PTS) have been shown in animal models to alter bone and cartilage development [151-154] and reduce birth weight[155], which has been shown to increase risk for osteoporosis and osteoarthritis [156]. These animal studies on PAE and PTS begin to explain some of the underlying mechanisms for the observed higher rates of osteoporosis and osteoarthritis [157, 158]. Moreover, alcohol exposure and smoking impact EV cargo [159, 160], potentially disrupting their normal role in angiogenesis and chondrogenesis [161, 162], processes that are crucial for proper bone and cartilage development in utero [163].

Additionally, osteoarthritis is associated with dysfunction of the primary cilia [164, 165], which is one region of the cell membrane that is particularly receptive to growth factors, such as those found in amniotic EVs. Primary cilia serve to directionally orient cell activities [166] and a rich aggregation of transmembrane receptors [167] in this specialized structure facilitates interactions between a cell and its environment to regulate cell growth. Primary cilia regulate bone growth [168, 169], and their loss [170, 171] can result in bone defects [172]. Cholesterol plays an integral role in two key components of primary cilium: cell membrane dynamics and ciliary sonic hedgehog signaling [173-175], and therefore, perturbations in cholesterol biosynthesis can disrupt cilia function, ultimately impacting bone growth and development and contributing to increased risk of osteoporosis and osteoarthritis. Maternal undernutrition [176] and PAE [177] are two of sources of early adversity that can result in dysregulated fetal cholesterol metabolism. Structural bone abnormalities often appear at birth in conditions such as these $[178,179]$ and in other ciliopathies [180]. To further investigate how cholesterol interferes with primary cilia, 7-dehydrocholesterol reductase (Dhcr7) and insulin-induced genes 1 and 2
(Insig1/2), genes regulating cholesterol metabolism, were mutated in osteoblasts. The mutant osteoblasts demonstrated dysregulated ciliary EV fusion which was ameliorated by the common cholesterol-reducing drug simvastatin [181]. This reveals that cholesterol metabolism disruption may be one means by which prenatal exposure impairs normal trafficking of $\mathrm{EVs}$, resulting in reduced delivery of crucial growth factors and mediators.

To investigate additional causative mechanisms, mouse chondrocytes were exposed to hypoxic conditions and assessed for primary cilia morphology and expression of hypoxia inducible factors (HIFs). Through knockdown and overexpression paradigms, HIF-2a demonstrated the ability to reduce primary cilia size and count in chondrocytes [165]. This effect may be mediated by EV trafficking, as HIFs have been identified in EVs [182], or by altered EV secretion, as HIFs have also been shown to induce release of EVs [183]. Altogether, this suggests that hypoxic conditions may result in a predisposition for osteoporosis and osteoarthritis. Developmental hypoxia comes in many forms: preeclampsia [184], placental insufficiency [185], gestational diabetes [186], childhood respiratory diseases [187], sleep apnea [188], etc.

In summary, developmental exposures can influence the growth factors and modulators carried by EVs and EV's interactions with primary cilia, which altogether interferes with bone and cartilage formation and integrity. Developmental exposures such as prenatal alcohol or hypoxia inhibit robust primary cilium formation resulting in poor regenerative capacity of cells and, over time, may result in premature symptomatic diseases of aging such as osteoporosis and osteoarthritis.

\subsection{EVs in the Developmental Origin of Adult-onset Neurodegeneration}

\section{2.i Alzheimer's disease}

Alzheimer's disease (AD) is another aging disease in which environmental factors during early development can result in later adverse health outcomes. As mentioned above, maternal alcohol consumption, causing an abnormal fetal neural maturation and a depletion of fetal neural stem cells during early development, can result in a decreased neural stem cell pool [63]. Consequently, residual stem cell activity in the affected adult may be inadequate to rescue memory deficits or repair dysfunctional synaptic and neural circuits [189-192], potentially increasing the risk while lowering the onset age for dementia and AD in individuals with FASD. Likewise, prenatal stressors during sensitive fetal periods and early environmental factors causing early developmental changes or deficits can have long-lasting 
effects in an individual, exacerbating AD-like neuropathological changes throughout one's lifespan [193, 194].

Current experimental evidence supports the hypothesis that amyloid beta $(\mathrm{A} \beta)$ plaque aggregation and an imbalance between production and clearance of the plaques and its peptides is an early index and initiating factor in $\operatorname{AD}[195,196]$. To understand how prenatal stressors can cause neuropathological changes in individuals, an animal study examined the age of onset and development of $A \beta$ plaques throughout the lifespan of male and female mouse offspring of dams prenatally exposed to auditory stress [197]. The authors discovered that, compared to the control mouse group, the prenatal auditory stress (PS) group exhibited earlier onset of beta amyloid pathology, with increased brain deposition of $A \beta$ plaques starting at 2 months. Likewise, PS significantly and persistently increased corticosterone levels in affected offspring compared to control groups, between 2 and 10 months of age and resulted in a persistent neuroendocrineaxis hyperactivity, enduring anxiety-like behavior, and cognitive and motor impairment across age. Overall, prenatal auditory stress significantly accelerated cognitive decline and $\mathrm{A} \beta$ plaque aggregation, characteristic of Alzheimer's disease, with female individuals of the PS group displaying a higher susceptibility for developing $\mathrm{AD}$.

\section{2.ii Parkinson's disease}

Parkinson's disease (PD) is an aging neurologic disease where environmental exposure during prenatal or early developmental period may be risk factors that have a longterm or an extended latency for PD's pathogenesis in an individual's later adult life. A possible explanation can be that the decreased population of nigrostriatal dopamine (DA) cell bodies early in life of an individual due to negative environmental exposure may speed up the DA system to reach decreased levels of DA cell bodies associated with PD when combined with normal agingrelated loss of the cell bodies later in life [198-200]. It is also possible that the neuronal damage in early development may make an individual more vulnerable to subsequent environmental risk factors to result in PD that may not have occurred without the prior developmental exposure. While dopaminergic neuronal death is a key pathological hallmark of PD [201], it is still unclear whether this pathogenesis is due to events that occurred during crucial development period or during adulthood or a combination of both. An animal study examined the effects of exposure to the environmental neurotoxicants, parquet (PQ) and maneb (MB), during a critical early developmental period and following re-exposure in adulthood [202]. Animals exposed at postnatal day 5-19, equivalent to human infantile period of 2 months to 3 years [203], to PQ or MB alone or in combination exhibited a reduction in tyrosine hydroxylase and dopamine transporter-positive neurons and decreased dopaminergic markers, within the nigrostriatal DA system. Moreover, these decreases were sustained even at 6 months of age, long after the initial exposure, suggesting a permanent inhibition of the DA system. This loss was reflected in progressive decrease in locomotor activity between 6-weeks and 6-months of age, which is consistent with progressive neurotoxicity. In addition to the permanent and progressive effects from early developmental exposures, adult exposure following the developmental exposure produced significantly greater reduction in both locomotor activity and nigral DA neuronal numbers, with increased striatal DA turnover (the ratio of (dihydroxyphenylacetic acid + homovanillic acid)/DA) and its metabolites. It strongly supports the hypothesis that neurotoxicant re-exposure during adulthood enhances the effects of developmental exposures and further disrupts and already vulnerable neural circuit.

Evidence from the above study supports the possibility that the effects of nigrostriatal system damage incurred during the developmental period may only be manifest with age progression and be exacerbated by additional neurotoxicant exposure. These data are consistent with the two-hit hypothesis of $\mathrm{DOHaD}$ outlined earlier. The neurotoxic exposure during early developmental period is the initial "hit" that results in permanent neurotoxicity to the DA system. Subsequent neurotoxic exposure or other stressors in adulthood act as the second "hit" that tips the already vulnerable balance to favor development of early PD onset.

\section{2.iii Extracellular Vesicles in Alzheimer's and Parkinson's Disease}

In a prenatally stressed environment, as described above, or in pathological conditions such as Alzheimer's or Parkinson's disease, it is possible that EVs act as active mediators in the progression of $\mathrm{AD}$ and $\mathrm{PD}$, by spreading the characteristic misfolded proteins like tau and $A \beta$ in AD or like $\alpha$-synuclein in PD [204, 205].

EVs observed from AD patient brains are enriched with $A \beta$-oligomers that are known to serve as vectors for inter-neuron transfer, propagating the AD pathology in a prion-like manner [206]. Furthermore, when EV formation and secretion are blocked by downregulating TSG101 and VPS4A proteins in vitro, the neuron-toneuron spread of $A \beta$-oligomer, and related toxicity was found to also be reduced [206]. Likewise, EVs appear to have the capacity to transfer $A \beta$ to extracellular space, as an in vitro study found excessive accumulation of EV 
marker protein, Alix, within amyloid plaques of AD brain sections while the brain of healthy controls lacked both the amyloid plaques as well as Alix protein [207]. A $\beta$ peptide results from enzymatic cleavage of amyloid precursor protein (APP). The imbalance between $A \beta$ peptide generation and clearance from the brain and its subsequent accumulation in the brain results in the characteristic amyloid plaque formation found in $\mathrm{AD}$ patients [208]. In neuronal cell cultures, EVs contain and transport full-length amyloid precursor protein (flAPP), APP metabolites as well as the enzymes required for cleaving flAPP [209, 210]. In addition, EVs can transfer hyper-phosphorylated Tau, considered to be a major neuropathological lesion in $\mathrm{AD}$, from microglia to neurons to spread this tauopathy in the brain of $\mathrm{AD}$ patients $[211,212]$. Taken together, the evidence for enrichment of $\mathrm{A} \beta$-oligomer and Tau in EVs from $\mathrm{AD}$ patient brains, as well as evidence cited previously showing that maternal auditory stress significantly increases $A \beta$ plaques in affected young-adult offspring, supports a hypothesis that EVs play a crucial mediating role in $\mathrm{AD}$ pathology, and in transducing the effects of early life experiences into early-onset $\mathrm{AD}$ pathology.

EVs have also recently been intensively examined for their role in the progression of Parkinson's disease in patients [205]. Current evidence supports the hypothesis that $\alpha$-synuclein $(\alpha-S y n)$ proteins play a critical role in common biochemical pathway important to the pathogenesis of PD [213, 214]. This disease selectively degrades dopaminergic neurons in the substantia nigra pars-compact, while the surviving neurons accumulate Lewy bodies that are composed of fibrillar $\alpha$-Syn and ubiquitinated proteins [215]. Inflammation and misfolded and aggregated $\alpha$-Syn proteins are key hallmarks of pathogenesis and progression of PD [213]. Research has shown that injured neurons release EVs containing misfolded $\alpha$-Syn, which can be taken up by other neurons and by glia, potentially resulting in transcellular spread of misfolded $\alpha$-Syn and activation of an inflammatory response [214]. It has also been noted that $\alpha$-Syn itself results in increased EV secretion by murine microgliatype cells, and that these EVs expressed increased Major Histocompatibility Complex (MHC) class II molecules and membrane TNF- $\alpha$ on their membrane surface [216] suggesting that $\alpha$-Syn-stimulated EVs may also spread inflammation. These EVs significantly increased the apoptosis rate in cortical neurons in vitro. Such EVmediated spread of $\alpha$-Syn protein may well exacerbate PD by decreasing the number and viability of neighboring healthy neurons while propagating inflammatory mediators to proximate glial cells, to promote concurrent inflammation. Another study observed that introduction of misfolded $\alpha$-Syn protein in an in vitro murine embryonic stem cell model resulted in reduced neural proliferation and decreased expression of neuronal markers while increasing neuronal apoptosis, all accompanied by reduced mRNA and protein levels of Notch-1, Hairy and enhancer of split-5 (Hes-5), and Notch intracellular domain (NICD) [217]. The same study also observed neurogenesis alterations in the hippocampal sub-granular zone in $\alpha$-Syn transgenic mice with decreased Notch-1, NICD, and Hes-5 expression. It is likely that EVs mediate the transfer of $\alpha$-Syn and other neuroinflammatory proteins in the brain both during early neurogenesis and in late adulthood to promote PD onset and progression.

Recent studies have also examined the role that EVs play in brain disorders and neurodegeneration due to their capacity to transfer miRNAs that can activate Toll-like receptors (TLRs) and the production of proinflammatory cytokines [218]. Several miRNAs, like miRNA-21, 29a, and let-7, have been documented to bind to TLRs 7-9, and subsequently activate NF- $\kappa \beta$ signalling and proinflammatory cytokine secretion [219]. While transient inflammation serves an important purpose in assisting the immune system to fight off infectious pathogens, prolonged inflammation during development and adulthood may contribute to neuronal dysfunctions and progression of neurodegenerative diseases such as $\mathrm{AD}$ and PD.

\subsection{EVs in the Developmental Origin of Cancer}

The lifetime probability of being diagnosed with cancer ranges from $38-40 \%$ and there were, in a predictive model, an estimated 1,806,590 new cases diagnosed in 2020 , of which 11,050 were in children (ages 0-14) and 5,800 were in adolescents (ages 15-19) [220]. While there are numerous types of cancer, the underlying pathogenesis is common to all. Genetic mutations and epigenetic reprogramming ultimately result in uncontrolled cellular proliferation and survival [221]. Moreover, EV signaling of these changes can seed tumor growth, promote transformation, protect tumors from immune response, and promote metastasis [222]. Exposures in utero and early childhood could be initial triggers of genetic mutations and epigenetic modifications since developmental and cancer biology are so closely linked [223, 224]. Tissue growth and differentiation is regulated by complex cellular processes that involve precise regulation of both cell division and apoptosis during prenatal and postnatal development. EVs have been shown to play a key role in these processes [225]. Because tumorigenesis is intimately linked to the processes of organogenesis, tissue growth and maturation [223], any perturbations during development in EV cargo and subsequent impact on these pathways that control these processes could promote transformation, making 
teratogens and other developmental insults tumorigenic both in developing cells and into adulthood.

If these mutations and epigenetic reprogramming occur in crucial, highly replicative tissues, then the consequences of in utero and childhood exposures may manifest relatively quickly as childhood cancer. One example of an early-onset cancer is neuroblastoma. For instance, evidence from a small case review of 13 children suggests that there are higher rates of neuroblastoma occurrence in children diagnosed with FASD than in the general population $(6 / 13$ or $46 \%$ vs. $10 \%$ in general population) [226]. Gene expression patterns in neuroblastoma are very similar to the expression pattern in neural crest cells, suggesting a common cellular origin, and also suggesting that the embryonic period of neural crest proliferation and migration may be vulnerable to in utero exposures which perturb the normal process of organogenesis [227]. PAE has been shown to alter neural crest migration, survival, oxidative stress response, and gene expression pattern [228]. Additionally, as mentioned previously, PAE alters EV cargo $[64,229,230]$, potentially perturbing to normal role of stem cell-derived
EVs as communicators in development [225] and modulators of oxidative stress response [231]. Ultimately, this phenomenon could at least contribute in part to the higher rate of neuroblastoma observed in children with FASD.

In other instances, the damage that results from accumulated in utero or childhood exposures may finally be manifest in adulthood. One well known example is the long-term consequences of diethylstilbestrol (DES) use during pregnancy on offspring, particularly female offspring who are more likely to develop cancers such as clear cell adenocarcinoma [232]. One study showed that DES upregulated specific miRNAs in fetal mouse thymocytes [233]. A number of these miRNAs have been identified in EVs [234] and are associated with cancer development such as breast, liver, brain, prostate, myometrial, and ovarian tumorigenesis [235, 236]. Altogether, this suggests these upregulated miRNAs target a number of proteins that may be involved in cellular survival, apoptosis, cell invasiveness, and oxidative stress common to many tissue types and potentially propagated by EV signaling.

\section{In Utero and Early Childhood Exposure}

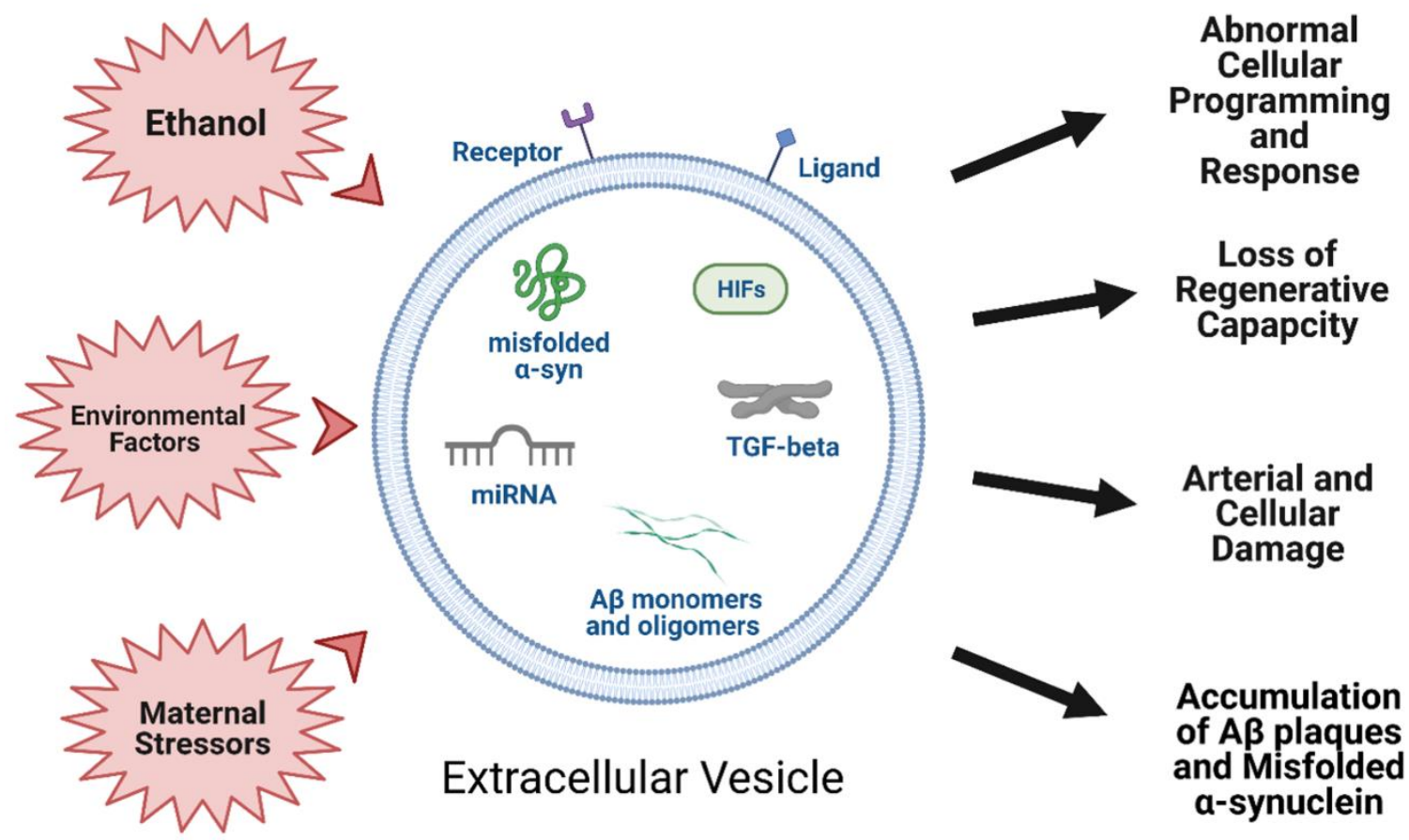

Figure 2. Early life exposures during pregnancy and childhood have the potential to alter extracellular vesicle composition and cargo that in turn has been shown perturb normal biological processes, contributing to the development of diseases. (Created with BioRender.com.) 
Immune surveillance also plays a critical role in preventing tumor growth and progression. Antigen presenting cells present tumor-specific antigens to effector immune cells (ex. NK cells, T cells) which subsequently target tumor cells for lysis, stopping tumorigenesis [237, 238]. Furthermore, a decrease in lymphocyte population and immunosuppression is associated with an increased risk of cancer development [237, 238]. Prenatal and childhood exposures have been linked to a decrease in immune cell populations and impaired function. For example, PAE impairs immune cell function in offspring [239] and of particular interest for tumorigenesis, it decreases $\mathrm{T}$ cell number in the thymus and peripheral blood and impairs $\mathrm{T}$ cell response to stimulation of proliferation in rats [240, 241]. These events may be mediated by EVs since they play an important role in immune cell maturation and activation [242-246], including direct and indirect antigen presentation to T cells [247]. Additionally, EVs carry immune modulatory molecules, such as cytokines, costimulatory/inhibitory molecules, growth factors [248250], that, if increase or decrease in EVs, may alter the expected $\mathrm{T}$ cell response to stimuli, affecting immune surveillance effectiveness against tumorigenesis. This is in agreement with the higher rates of cancer observed in individuals with FASD aged 18-44 compared to general population $(3.75 \%$ FASD vs. $2.0 \%$, general population, 1.9 fold higher) [158]. And this pattern is seen again in PTS exposure and second-hand smoking (SHS) in childhood. One study showed suppressed function of cytotoxic T-cell lymphocytes (CD8+), which resulted in increased successful seeding of lymphoma cells and subsequently more rapid tumor growth in PTS mouse pups [251]. Another study showed similarly suppressed CD8+ function, this time against viral infection [252]. Interestingly, in a rat model of allographic liver transplant, EVs from regulatory $T$ cells were sufficient to decrease CD8+ proliferation and allograft transplant rejection [253], indicating that if EVs are similarly altered following PTS/SHS, they could mediate the suppression of CD8+. This impaired immune cell function could contribute to the observed higher rate of childhood cancers in children exposed to SHS [254] and could increase risk for cancer in early adulthood as more cellular damage accumulates from SHS [255-257].

\section{Conclusions}

While diseases such as CVD, osteoporosis, osteoarthritis, and dementia are typically regarded as diseases of aging, it is important to consider their possible developmental origins. Environmental perturbations during the prenatal period and early childhood may increase risk of these diseases in adulthood and potentially lead to early onset in affected individuals as a result of earlier accumulation of damage. Review of the literature suggests that EVs are possible mediators of the long-term consequences of early life experiences, either directly, by contributing to impaired tissue development, or indirectly, by contributing to the accumulation of additional risk factors like the spread of mis-folded proteins which mediate adult-onset disease. As revealed by our review of the literature, there is a lack of studies focused on the direct question of how EVs mediate progression of diseases of developmental origins. Additional research is needed to more clearly elucidate these mechanisms beyond the relationships we have described above. By gaining a better understanding of how early life influences lead to so many common diseases of the aging, it may be possible to identify those with increased risk at an earlier age. Potential early identification of risk raises the exciting possibility of increased time for interventions to mitigate disease progression allowing for better control of chronic diseases.

\section{Acknowlegements}

This work was supported by the National Institutes of Health [R01AA024659 to RCM, F30AA027698 to MRP, F31AA028446 to DDC].

\section{Conflict of interest statement}

The authors declare no conflict of interest.

\section{References}

[1] Barker DJP, Godfrey KM, Gluckman PD, Harding JE, Owens JA, Robinson JS (1993). Fetal nutrition and cardiovascular disease in adult life. The Lancet, 341:938-941.

[2] Barker DJ (1995). Fetal origins of coronary heart disease. BMJ (Clinical research ed.), 311:171-174.

[3] Barker DJP (2002). Fetal programming of coronary heart disease. Trends in Endocrinology \& Metabolism, 13:364-368.

[4] Fleming AS, O’Day DH, Kraemer GW (1999). Neurobiology of mother-infant interactions: experience and central nervous system plasticity across development and generations. Neuroscience \& Biobehavioral Reviews, 23:673-685.

Lunde ER, Washburn SE, Golding MC, Bake S, Miranda RC, Ramadoss J (2016). Alcohol-Induced Developmental Origins of Adult-Onset Diseases. Alcoholism, clinical and experimental research, 40:1403-1414.

[6] Veazey KJ, Parnell SE, Miranda RC, Golding MC (2015). Dose-dependent alcohol-induced alterations in chromatin structure persist beyond the window of exposure and correlate with fetal alcohol syndrome 
birth defects. Epigenetics \& chromatin, 8:39-39.

[7] Gavin DP, Grayson DR, Varghese SP, Guizzetti M (2017). Chromatin Switches during Neural Cell Differentiation and Their Dysregulation by Prenatal Alcohol Exposure. Genes (Basel), 8.

[8] Knudson AG, Jr. (1971). Mutation and cancer: statistical study of retinoblastoma. Proceedings of the National Academy of Sciences of the United States of America, 68:820-823.

[9] Barker DJ, Bull AR, Osmond C, Simmonds SJ (1990). Fetal and placental size and risk of hypertension in adult life. BMJ (Clinical research ed.), 301:259-262.

[10] Eriksson J, Forsén T, Tuomilehto J, Osmond C, Barker D (2000). Fetal and Childhood Growth and Hypertension in Adult Life. Hypertension, 36:790-794.

[11] Barker David JP, Osmond C, Forsen Tom J, Kajantie E, Eriksson Johan G (2007). Maternal and Social Origins of Hypertension. Hypertension, 50:565-571.

[12] Osmond C, Kajantie E, Forsén Tom J, Eriksson Johan G, Barker David JP (2007). Infant Growth and Stroke in Adult Life. Stroke, 38:264-270.

[13] Eriksson JG, Forsén T, Tuomilehto J, Osmond C, Barker DJP (2000). Early Growth, Adult Income, and Risk of Stroke. Stroke, 31:869-874.

[14] Basha MR, Wei W, Bakheet SA, Benitez N, Siddiqi HK, Ge Y-W, et al. (2005). The fetal basis of amyloidogenesis: exposure to lead and latent overexpression of amyloid precursor protein and betaamyloid in the aging brain. The Journal of neuroscience : the official journal of the Society for Neuroscience, 25:823-829.

[15] Bakulski KM, Rozek LS, Dolinoy DC, Paulson HL, $\mathrm{Hu} \mathrm{H}$ (2012). Alzheimer's disease and environmental exposure to lead: the epidemiologic evidence and potential role of epigenetics. Current Alzheimer research, 9:563-573.

[16] Cooper C, Javaid MK, Taylor P, Walker-Bone K, Dennison E, Arden N (2002). The Fetal Origins of Osteoporotic Fracture. Calcified Tissue International, 70:391-394.

[17] Wood C, Stenson C, Embleton N (2015). The Developmental Origins of Osteoporosis. Current Genomics, 16:1-1.

[18] Chen ML, Olson HC, Picciano JF, Starr JR, Owens J (2012). Sleep problems in children with fetal alcohol spectrum disorders. J Clin Sleep Med, 8:421-429.

[19] Goril S, Zalai D, Scott L, Shapiro CM (2016). Sleep and melatonin secretion abnormalities in children and adolescents with fetal alcohol spectrum disorders. Sleep Med, 23:59-64.

[20] Ipsiroglu OS, Wind K, Hung YA, Berger M, Chan F, $\mathrm{Yu}$ W, et al. (2019). Prenatal alcohol exposure and sleep-wake behaviors: exploratory and naturalistic observations in the clinical setting and in an animal model. Sleep Med, 54:101-112.

[21] Lewin M, Ilina M, Betz J, Masiello K, Hui M, Wilson DA, et al. (2018). Developmental Ethanol-Induced Sleep Fragmentation, Behavioral Hyperactivity, Cognitive Impairment and Parvalbumin Cell Loss are Prevented by Lithium Co-treatment. Neuroscience,
369:269-277.

Malow BA, Findling RL, Schroder CM, Maras A, Breddy J, Nir T, et al. (2020). Sleep, Growth, and Puberty After 2 Years of Prolonged-Release Melatonin in Children With Autism Spectrum Disorder. J Am Acad Child Adolesc Psychiatry.

[23] Ramos AR, Tarraf W, Wu B, Redline S, Cai J, Daviglus ML, et al. (2020). Sleep and neurocognitive decline in the Hispanic Community Health Study/Study of Latinos. Alzheimers Dement, 16:305315.

[24] Yates JF, Troester MM, Ingram DG (2018). Sleep in Children with Congenital Malformations of the Central Nervous System. Curr Neurol Neurosci Rep, 18:38.

[25] Stone KC, LaGasse LL, Lester BM, Shankaran S, Bada HS, Bauer CR, et al. (2010). Sleep problems in children with prenatal substance exposure: the Maternal Lifestyle study. Arch Pediatr Adolesc Med, 164:452-456.

[26] Dasgupta C, Xiao D, Xu Z, Yang S, Zhang L (2012). Developmental nicotine exposure results in programming of alveolar simplification and interstitial pulmonary fibrosis in adult male rats. Reprod Toxicol, 34:370-377.

[27] Mouralidarane A, Soeda J, Sugden D, Bocianowska A, Carter R, Ray S, et al. (2015). Maternal obesity programs offspring non-alcoholic fatty liver disease through disruption of 24-h rhythms in mice. Int J Obes (Lond), 39:1339-1348.

[28] Zhu Y, Zuo N, Li B, Xiong Y, Chen H, He H, et al. (2018). The expressional disorder of the renal RAS mediates nephrotic syndrome of male rat offspring induced by prenatal ethanol exposure. Toxicology, 400-401:9-19.

[29] Yu Y, Du H, Wei S, Feng L, Li J, Yao F, et al. (2018). Adipocyte-Derived Exosomal MiR-27a Induces Insulin Resistance in Skeletal Muscle Through Repression of PPARgamma. Theranostics, 8:21712188.

[30] Eck SR, Ardekani CS, Salvatore M, Luz S, Kim ED, Rogers CM, et al. (2020). The effects of early life adversity on growth, maturation, and steroid hormones in male and female rats. Eur J Neurosci, 52:2664-2680. [31] Yam KY, Ruigrok SR, Ziko I, De Luca SN, Lucassen PJ, Spencer SJ, et al. (2017). Ghrelin and hypothalamic NPY/AgRP expression in mice are affected by chronic early-life stress exposure in a sexspecific manner. Psychoneuroendocrinology, 86:7377.

[32] Glendining KA, Higgins MBA, Fisher LC, Jasoni CL (2020). Maternal obesity modulates sexually dimorphic epigenetic regulation and expression of leptin receptor in offspring hippocampus. Brain Behav Immun, 88:151-160.

[33] Chen M, Wang X, Hu Z, Zhou H, Xu Y, Qiu L, et al. (2017). Programming of mouse obesity by maternal exposure to concentrated ambient fine particles. Part Fibre Toxicol, 14:20.

[34] Clarke MA, Joshu CE (2017). Early Life Exposures 
and Adult Cancer Risk. Epidemiol Rev, 39:11-27.

[35] Stacy SL, Buchanich JM, Ma ZQ, Mair C, Robertson L, Sharma RK, et al. (2019). Maternal Obesity, Birth Size, and Risk of Childhood Cancer Development. Am J Epidemiol, 188:1503-1511.

[36] Riley EP, Infante MA, Warren KR (2011). Fetal Alcohol Spectrum Disorders: An Overview. Neuropsychology Review, 21:73.

[37] Sokol RJ, Delaney-Black V, Nordstrom B (2003). Fetal Alcohol Spectrum Disorder. JAMA, 290:29962999.

[38] May PA, Chambers CD, Kalberg WO, Zellner J, Feldman H, Buckley D, et al. (2018). Prevalence of Fetal Alcohol Spectrum Disorders in 4 US Communities. Jama, 319:474-482.

[39] Bakhireva LN, Sharkis J, Shrestha S, MirandaSohrabji TJ, Williams S, Miranda RC (2017). Prevalence of Prenatal Alcohol Exposure in the State of Texas as Assessed by Phosphatidylethanol in Newborn Dried Blood Spot Specimens. Alcoholism: Clinical and Experimental Research, 41:1004-1011.

[40] Umer A, Lilly C, Hamilton C, Baldwin A, Breyel J, Tolliver A, et al. (2020). Prevalence of alcohol use in late pregnancy. Pediatr Res, 88:312-319.

[41] Finer LB, Zolna MR (2014). Shifts in intended and unintended pregnancies in the United States, 20012008. American journal of public health, 104 Suppl 1:S43-S48.

[42] Pennington JS, Shuvaeva TI, Pennington SN (2002). Maternal dietary ethanol consumption is associated with hypertriglyceridemia in adult rat offspring. Alcohol Clin Exp Res, 26:848-855.

[43] Nguyen VB, Probyn ME, Campbell F, Yin KV, Samuel CS, Zimanyi MA, et al. (2014). Low-dose maternal alcohol consumption: effects in the hearts of offspring in early life and adulthood. Physiol Rep, 2.

[44] Reid N, Akison LK, Hoy W, Moritz KM (2019). Adverse Health Outcomes Associated With Fetal Alcohol Exposure: A Systematic Review Focused on Cardio-Renal Outcomes. Journal of Studies on Alcohol and Drugs, 80:515-523.

[45] Cook JC, Lynch ME, Coles CD (2019). Association Analysis: Fetal Alcohol Spectrum Disorder and Hypertension Status in Children and Adolescents. Alcoholism: Clinical and Experimental Research, 43:1727-1733.

[46] Johnson S, Knight R, Marmer DJ, Steele RW (1981). Immune deficiency in fetal alcohol syndrome. Pediatr Res, 15:908-911.

[47] Oleson DR, Magee RM, Donahoe RM, Falek A, Coles CD (1998). Immunity and prenatal alcohol exposure. A pilot study in human adolescents. Adv Exp Med Biol, 437:255-264.

[48] Reid N, Moritz KM, Akison LK (2019). Adverse health outcomes associated with fetal alcohol exposure: A systematic review focused on immunerelated outcomes. Pediatric Allergy and Immunology, 30:698-707.

[49] Zhang X, Sliwowska JH, Weinberg J (2005). Prenatal alcohol exposure and fetal programming: effects on neuroendocrine and immune function. Exp Biol Med (Maywood), 230:376-388.

[50] Raineki C, Bodnar TS, Holman PJ, Baglot SL, Lan N, Weinberg J (2017). Effects of early-life adversity on immune function are mediated by prenatal environment: Role of prenatal alcohol exposure. Brain Behav Immun, 66:210-220.

[51] Bodnar TS, Hill LA, Weinberg J (2016). Evidence for an immune signature of prenatal alcohol exposure in female rats. Brain Behav Immun, 58:130-141.

[52] Castells S, Mark E, Abaci F, Schwartz E (1981). Growth retardation in fetal alcohol syndrome. Unresponsiveness to growth-promoting hormones. Dev Pharmacol Ther, 3:232-241.

[53] Chen L, Nyomba BLG (2003). Effects of prenatal alcohol exposure on glucose tolerance in the rat offspring. Metabolism, 52:454-462.

[54] Gårdebjer EM, Anderson ST, Pantaleon M, Wlodek ME, Moritz KM (2015). Maternal alcohol intake around the time of conception causes glucose intolerance and insulin insensitivity in rat offspring, which is exacerbated by a postnatal high-fat diet. Faseb j, 29:2690-2701.

[55] Akison LK, Reid N, Wyllie M, Moritz KM (2019). Adverse Health Outcomes in Offspring Associated With Fetal Alcohol Exposure: A Systematic Review of Clinical and Preclinical Studies With a Focus on Metabolic and Body Composition Outcomes. Alcoholism: Clinical and Experimental Research, 43:1324-1343.

[56] Bake S, Tingling JD, Miranda RC (2012). Ethanol exposure during pregnancy persistently attenuates cranially directed blood flow in the developing fetus: evidence from ultrasound imaging in a murine second trimester equivalent model. Alcoholism, clinical and experimental research, 36:748-758.

[57] Barker D, Hanson M (2004). Altered regional blood flow in the fetus: the origins of cardiovascular disease? Acta Paediatrica, 93:1559-1560.

[58] Nathanielsz P, Hanson M (2003). PERSPECTIVES. The fetal dilemma: spare the brain and spoil the liver. Journal of Physiology-london - J PHYSIOLLONDON, 548:333-333.

[59] Gray S, Denton K, Cullen-McEwen L, Bertram J, Moritz K (2010). Prenatal Exposure to Alcohol Reduces Nephron Number and Raises Blood Pressure in Progeny. Journal of the American Society of Nephrology : JASN, 21:1891-1902.

[60] Keller G, Zimmer G, Mall G, Ritz E, Amann K (2003). Nephron Number in Patients with Primary Hypertension. New England Journal of Medicine, 348:101-108.

[61] Meissner A (2016). Hypertension and the Brain: A Risk Factor for More Than Heart Disease. Cerebrovascular Diseases, 42:255-262.

[62] Camarillo C, Kumar LS, Bake S, Sohrabji F, Miranda RC (2007). Ethanol regulates angiogenic cytokines during neural development: evidence from an in vitro model of mitogen-withdrawal-induced cerebral cortical neuroepithelial differentiation. Alcoholism, 
clinical and experimental research, 31:324-335.

[63] Santillano DR, Kumar LS, Prock TL, Camarillo C, Tingling JD, Miranda RC (2005). Ethanol induces cell-cycle activity and reduces stem cell diversity to alter both regenerative capacity and differentiation potential of cerebral cortical neuroepithelial precursors. BMC Neuroscience, 6:59.

[64] Tseng AM, Chung DD, Pinson MR, Salem NA, Eaves SE, Miranda RC (2019). Ethanol Exposure Increases miR-140 in Extracellular Vesicles: Implications for Fetal Neural Stem Cell Proliferation and Maturation. Alcoholism, clinical and experimental research, 43:1414-1426.

[65] Tincer G, Mashkaryan V, Bhattarai P, Kizil C (2016). Neural stem/progenitor cells in Alzheimer's disease. The Yale journal of biology and medicine, 89:23-35.

[66] Savage DD, Becher M, de la Torre AJ, Sutherland RJ (2002). Dose-dependent effects of prenatal ethanol exposure on synaptic plasticity and learning in mature offspring. Alcohol Clin Exp Res, 26:1752-1758.

[67] Sanchez LM, Goss J, Wagner J, Davies S, Savage DD, Hamilton DA, et al. (2019). Moderate prenatal alcohol exposure impairs performance by adult male rats in an object-place paired-associate task. Behav Brain Res, 360:228-234

[68] Hollands C, Bartolotti N, Lazarov O (2016). Alzheimer's Disease and Hippocampal Adult Neurogenesis; Exploring Shared Mechanisms. Frontiers in Neuroscience, 10.

[69] Drake P, Driscoll A, Mathews TJ. 2016. Cigarette Smoking During Pregnancy: United States, 2016. CDC, editor.

[70] A. Slotkin T, Greer N, Faust J, Cho H, J. Seidler F (1986). Effects of maternal nicotine injections on brain development in the rat: Ornithine decarboxylase activity, nucleic acids and proteins in discrete brain regions. Brain Research Bulletin, 17:41-50.

[71] Slotkin TA, Orband-Miller L, Queen KL, Whitmore WL, Seidler FJ (1987). Effects of prenatal nicotine exposure on biochemical development of rat brain regions: maternal drug infusions via osmotic minipumps. Journal of Pharmacology and Experimental Therapeutics, 240:602.

[72] Wickström R (2007). Effects of nicotine during pregnancy: human and experimental evidence. Current neuropharmacology, 5:213-222.

[73] Butler NR, Goldstein H (1973). Smoking in pregnancy and subsequent child development. British medical journal, 4:573-575.

[74] Holloway AC, Lim GE, Petrik JJ, Foster WG, Morrison KM, Gerstein HC (2005). Fetal and neonatal exposure to nicotine in Wistar rats results in increased beta cell apoptosis at birth and postnatal endocrine and metabolic changes associated with type 2 diabetes. Diabetologia, 48:2661-2666.

[75] Bruin JE, Gerstein HC, Holloway AC (2010). Longterm consequences of fetal and neonatal nicotine exposure: a critical review. Toxicological sciences : an official journal of the Society of Toxicology, 116:364374.
[76]

Bennett HA, Einarson A, Taddio A, Koren G, Einarson TR (2004). Prevalence of Depression During Pregnancy: Systematic Review. Obstetrics \& Gynecology, 103.

[77] Nemoda Z, Massart R, Suderman M, Hallett M, Li T, Coote M, et al. (2015). Maternal depression is associated with DNA methylation changes in cord blood $\mathrm{T}$ lymphocytes and adult hippocampi. Translational psychiatry, 5:e545-e545.

[78] Lu HQ, Hu R (2019). Lasting Effects of Intrauterine Exposure to Preeclampsia on Offspring and the Underlying Mechanism. AJP reports, 9:e275-e291.

[79] Kajantie E, Eriksson Johan G, Osmond C, Thornburg K, Barker David JP (2009). Pre-Eclampsia Is Associated With Increased Risk of Stroke in the Adult Offspring. Stroke, 40:1176-1180.

[80] Alastalo H, Räikkönen K, Pesonen A-K, Osmond C, Barker DJP, Kajantie E, et al. (2009). Cardiovascular health of Finnish war evacuees 60 years later. Annals of Medicine, 41:66-72.

[81] Felitti VJ, Anda RF, Nordenberg D, Williamson DF, Spitz AM, Edwards V, et al. (2019). REPRINT OF: Relationship of Childhood Abuse and Household Dysfunction to Many of the Leading Causes of Death in Adults: The Adverse Childhood Experiences (ACE) Study. American Journal of Preventive Medicine, 56:774-786.

[82] Dong M, Giles Wayne H, Felitti Vincent J, Dube Shanta R, Williams Janice E, Chapman Daniel P, et al. (2004). Insights Into Causal Pathways for Ischemic Heart Disease. Circulation, 110:1761-1766.

[83] Tetta C, Ghigo E, Silengo L, Deregibus MC, Camussi $\mathrm{G}$ (2013). Extracellular vesicles as an emerging mechanism of cell-to-cell communication. Endocrine, 44:11-19.

[84] Drago D, Cossetti C, Iraci N, Gaude E, Musco G, Bachi A, et al. (2013). The stem cell secretome and its role in brain repair. Biochimie, 95:2271-2285.

[85] Johnstone RM, Adam M, Hammond JR (1987). Vesicle formation during reticulocyte maturation. Association of plasma membrane activities with released vesicles (exosomes). Journal of Biological Chemistry, 262:9412-9420.

[86] Stein JM, Luzio JP (1991). Ectocytosis caused by sublytic autologous complement attack on human neutrophils. The sorting of endogenous plasmamembrane proteins and lipids into shed vesicles. Biochemical Journal, 274:381-386.

[87] Cocucci E, Meldolesi J (2015). Ectosomes and exosomes: shedding the confusion between extracellular vesicles. Trends in Cell Biology, 25:364372.

[88] Thery C, Ostrowski M, Segura E (2009). Membrane vesicles as conveyors of immune responses. Nat Rev Immunol, 9:581-593.

[89] Thery C, Zitvogel L, Amigorena S (2002). Exosomes: composition, biogenesis and function. Nat Rev Immunol, 2:569-579.

[90] Ito M, Yoshimoto T, Kawabori M, Fujimoto S, Yamauchi T, Yamaguchi H, et al. (2013). Diagnostic 
impact of baseline cerebral blood flow in patients with acute ischemic stroke prior to intravenous recombinant tissue plasminogen activator therapy. Clin Neurol Neurosurg, 115:1464-1469.

[91] Lawson C, Vicencio JM, Yellon DM, Davidson SM (2016). Microvesicles and exosomes: new players in metabolic and cardiovascular disease. J Endocrinol, 228:R57-71.

[92] Mulcahy LA, Pink RC, Carter DRF (2014). Routes and mechanisms of extracellular vesicle uptake. Journal of extracellular vesicles, 3:10.3402/jev.v3403.24641.

[93] Bruno S, Porta S, Bussolati B (2016). Extracellular vesicles in renal tissue damage and regeneration. Eur J Pharmacol, 790:83-91.

[94] Zhan C, Ma CB, Yuan HM, Cao BY, Zhu JJ (2015). Macrophage-derived microvesicles promote proliferation and migration of Schwann cell on peripheral nerve repair. Biochem Biophys Res Commun, 468:343-348.

[95] Gai C, Carpanetto A, Deregibus MC, Camussi G (2016). Extracellular vesicle-mediated modulation of angiogenesis. Histol Histopathol, 31:379-391.

[96] Grange C, Iampietro C, Bussolati B (2017). Stem cell extracellular vesicles and kidney injury. Stem Cell Investig, 4:90.

[97] Mahnke AH, Miranda RC, Homanics GE (2017). Epigenetic mediators and consequences of excessive alcohol consumption. Alcohol, 60:1-6.

[98] Miranda RC. 2014. Chapter Seven - MicroRNAs and Ethanol Toxicity. In International Review of Neurobiology. S.C. Pandey, editor: Academic Press. 245-284.

[99] Chuang JC, Jones PA (2007). Epigenetics and MicroRNAs. Pediatric Research, 61:24-29.

[100] Balaraman S, Lunde ER, Sawant O, Cudd TA, Washburn SE, Miranda RC (2014). Maternal and neonatal plasma microRNA biomarkers for fetal alcohol exposure in an ovine model. Alcoholism, clinical and experimental research, 38:1390-1400.

[101] Stuendl A, Kunadt M, Kruse N, Bartels C, Moebius W, Danzer KM, et al. (2016). Induction of $\alpha$-synuclein aggregate formation by CSF exosomes from patients with Parkinson's disease and dementia with Lewy bodies. Brain, 139:481-494.

[102] Fiandaca MS, Kapogiannis D, Mapstone M, Boxer A, Eitan E, Schwartz JB, et al. (2015). Identification of preclinical Alzheimer's disease by a profile of pathogenic proteins in neurally derived blood exosomes: A case-control study. Alzheimers Dement, 11:600-607 e601.

[103] Ghidoni R, Squitti R, Siotto M, Benussi L (2018). Innovative Biomarkers for Alzheimer's Disease: Focus on the Hidden Disease Biomarkers. J Alzheimers Dis, 62:1507-1518.

[104] Mahnke AH, Sideridis GD, Salem NA, Tseng AM, Carter RC, Dodge NC, et al. (2021). Infant circulating MicroRNAs as biomarkers of effect in fetal alcohol spectrum disorders. Scientific Reports, 11:1429.

[105] Lakkaraju A, Rodriguez-Boulan E (2008). Itinerant exosomes: emerging roles in cell and tissue polarity. Trends in Cell Biology, 18:199-209.

[106] Dickhout A, Koenen RR (2018). Extracellular Vesicles as Biomarkers in Cardiovascular Disease; Chances and Risks. Frontiers in cardiovascular medicine, 5:113-113.

[107] Ceafalan L, Ioghen OC, Marta D, Constantin A, Alexandru N, Nemecz M, et al. 2019. Part Two: Extracellular Vesicles as a Risk Factor in Neurodegenerative Diseases.

[108] Murphy C, Withrow J, Hunter M, Liu Y, Tang YL, Fulzele S, et al. (2018). Emerging role of extracellular vesicles in musculoskeletal diseases. Molecular aspects of medicine, 60:123-128.

[109] Rich-Edwards JW, Stampfer MJ, Manson JE, Rosner B, Hankinson SE, Colditz GA, et al. (1997). Birth weight and risk of cardiovascular disease in a cohort of women followed up since 1976. BMJ, 315:396-400.

[110] Martyn CN, Greenwald SE (1997). Impaired synthesis of elastin in walls of aorta and large conduit arteries during early development as an initiating event in pathogenesis of systemic hypertension. The Lancet, 350:953-955.

[111] Martyn CN, Meade TW, Stirling Y, Barker DJP (1995). Plasma concentrations of fibrinogen and factor VII in adult life and their relation to intra-uterine growth. British Journal of Haematology, 89:142-146.

[112] Wilhelmsen L, Svärdsudd K, Korsan-Bengtsen K, Larsson B, Welin L, Tibblin G (1984). Fibrinogen as a Risk Factor for Stroke and Myocardial Infarction. New England Journal of Medicine, 311:501-505.

[113] Hoffman JIE, Kaplan S (2002). The incidence of congenital heart disease. Journal of the American College of Cardiology, 39:1890-1900.

[114] Raissadati A, Nieminen H, Haukka J, Sairanen H, Jokinen E (2016). Late Causes of Death After Pediatric Cardiac Surgery: A 60-Year PopulationBased Study. J Am Coll Cardiol, 68:487-498.

[115] Brickner ME, Hillis LD, Lange RA (2000). Congenital heart disease in adults. First of two parts. N Engl J Med, 342:256-263.

[116] Kaemmerer H, Bauer U, de Haan F, Flesch J, GohlkeBärwolf C, Hagl S, et al. (2011). Recommendations for improving the quality of the interdisciplinary medical care of grown-ups with congenital heart disease (GUCH). Int J Cardiol, 150:59-64.

[117] Mandalenakis Z, Rosengren A, Lappas G, Eriksson P, Hansson PO, Dellborg M (2016). Ischemic Stroke in Children and Young Adults With Congenital Heart Disease. Journal of the American Heart Association, 5:e003071.

[118] Billett J, Cowie MR, Gatzoulis MA, Vonder Muhll IF, Majeed A (2008). Comorbidity, healthcare utilisation and process of care measures in patients with congenital heart disease in the UK: cross-sectional, population-based study with case-control analysis. Heart, 94:1194-1199.

[119] Moons P, Van Deyk K, Dedroog D, Troost E, Budts W (2006). Prevalence of cardiovascular risk factors in adults with congenital heart disease. Eur J Cardiovasc 
Prev Rehabil, 13:612-616.

[120] Bokma JP, Zegstroo I, Kuijpers JM, Konings TC, van Kimmenade RRJ, van Melle JP, et al. (2018). Factors associated with coronary artery disease and stroke in adults with congenital heart disease. Heart, 104:574580.

[121] Videbæk J, Laursen HB, Olsen M, Høfsten DE, Johnsen SP (2016). Long-Term Nationwide FollowUp Study of Simple Congenital Heart Disease Diagnosed in Otherwise Healthy Children. Circulation, 133:474-483.

[122] Schwartz SS, Madsen N, Laursen HB, Hirsch R, Olsen MS (2018). Incidence and Mortality of Adults With Pulmonary Hypertension and Congenital Heart Disease. The American Journal of Cardiology, 121:1610-1616.

[123] Olsen M, Marino B, Kaltman J, Laursen H, Jakobsen L, Mahle W, et al. (2017). Myocardial Infarction in Adults With Congenital Heart Disease. Am J Cardiol, 120:2272-2277.

[124] Lin Y-S, Liu P-H, Wu L-S, Chen Y-M, Chang C-J, Chu P-H (2014). Major adverse cardiovascular events in adult congenital heart disease: a population-based follow-up study from Taiwan. BMC Cardiovascular Disorders, 14:38.

[125] Gu H, Chen L, Xue J, Huang T, Wei X, Liu D, et al. (2019). Expression profile of maternal circulating microRNAs as non-invasive biomarkers for prenatal diagnosis of congenital heart defects. Biomed Pharmacother, 109:823-830.

[126] Wu KH, Xiao QR, Yang Y, Xu JL, Zhang F, Liu CM, et al. (2018). MicroRNA-34a modulates the Notch signaling pathway in mice with congenital heart disease and its role in heart development. J Mol Cell Cardiol, 114:300-308.

[127] Xie WQ, Zhou L, Chen Y, Ni B (2016). Circulating microRNAs as potential biomarkers for diagnosis of congenital heart defects. World J Emerg Med, 7:85-89.

[128] Zamani P, Fereydouni N, Butler AE, Navashenaq JG, Sahebkar A (2019). The therapeutic and diagnostic role of exosomes in cardiovascular diseases. Trends Cardiovasc Med, 29:313-323.

[129] Li D, Ji L, Liu L, Liu Y, Hou H, Yu K, et al. (2014). Characterization of circulating microRNA expression in patients with a ventricular septal defect. PLoS One, 9:e106318.

[130] Wu F, Yin Z, Yang L, Fan J, Xu J, Jin Y, et al. (2019). Smoking Induced Extracellular Vesicles Release and Their Distinct Properties in Non-Small Cell Lung Cancer. Journal of Cancer, 10:3435-3443.

[131] Wang J, Greene SB, Bonilla-Claudio M, Tao Y, Zhang J, Bai Y, et al. (2010). Bmp Signaling Regulates Myocardial Differentiation from Cardiac Progenitors Through a MicroRNA-Mediated Mechanism. Developmental Cell, 19:903-912.

[132] Gao YJ, Holloway AC, Zeng ZH, Lim GE, Petrik JJ, Foster WG, et al. (2005). Prenatal exposure to nicotine causes postnatal obesity and altered perivascular adipose tissue function. Obes Res, 13:687-692.

[133] Raghuveer G, White DA, Hayman LL, Woo JG,
Villafane J, Celermajer D, et al. (2016). Cardiovascular Consequences of Childhood Secondhand Tobacco Smoke Exposure: Prevailing Evidence, Burden, and Racial and Socioeconomic Disparities: A Scientific Statement From the American Heart Association. Circulation, 134:e336-e359.

[134] Entringer S (2013). Impact of stress and stress physiology during pregnancy on child metabolic function and obesity risk. Current opinion in clinical nutrition and metabolic care, 16:320-327.

[135] Godoy LC, Frankfurter C, Cooper M, Lay C, Maunder R, Farkouh ME (2020). Association of Adverse Childhood Experiences With Cardiovascular Disease Later in Life: A Review. JAMA Cardiology.

[136] Sharma H, Chinnappan M, Agarwal S, Dalvi P, Gunewardena S, O'Brien-Ladner A, et al. (2018). Macrophage-derived extracellular vesicles mediate smooth muscle hyperplasia: role of altered miRNA cargo in response to HIV infection and substance abuse. FASEB journal : official publication of the Federation of American Societies for Experimental Biology, 32:5174-5185.

[137] Shahjin F, Guda RS, Schaal VL, Odegaard K, Clark A, Gowen A, et al. (2019). Brain-Derived Extracellular Vesicle microRNA Signatures Associated with In Utero and Postnatal Oxycodone Exposure. Cells, 9:21.

[138] Lin X, He Y, Hou X, Zhang Z, Wang R, Wu Q (2016). Endothelial Cells Can Regulate Smooth Muscle Cells in Contractile Phenotype through the miR206/ARF6\&NCX1/Exosome Axis. PLOS ONE, $11: \mathrm{e} 0152959$.

[139] Wang L-L, Zhang Z, Li Q, Yang R, Pei X, Xu Y, et al. (2008). Ethanol exposure induces differential microRNA and target gene expression and teratogenic effects which can be suppressed by folic acid supplementation. Human Reproduction, 24:562-579.

[140] Pienimaeki-Roemer A, Konovalova T, Musri MM, Sigruener A, Boettcher A, Meister G, et al. (2017). Transcriptomic profiling of platelet senescence and platelet extracellular vesicles. Transfusion, 57:144156.

[141] Nguyen MA, Karunakaran D, Geoffrion M, Cheng HS, Tandoc K, Perisic Matic L, et al. (2018). Extracellular Vesicles Secreted by Atherogenic Macrophages Transfer MicroRNA to Inhibit Cell Migration. Arterioscler Thromb Vasc Biol, 38:49-63.

[142] Wagschal A, Najafi-Shoushtari SH, Wang L, Goedeke L, Sinha S, deLemos AS, et al. (2015). Genome-wide identification of microRNAs regulating cholesterol and triglyceride homeostasis. Nature Medicine, 21:1290-1297.

[143] Lippai D, Bala S, Catalano D, Kodys K, Szabo G (2014). Micro-RNA-155 deficiency prevents alcoholinduced serum endotoxin increase and small bowel inflammation in mice. Alcoholism, clinical and experimental research, 38:2217-2224.

[144] Zheng B, Yin W-N, Suzuki T, Zhang X-H, Zhang Y, Song L-L, et al. (2017). Exosome-Mediated miR-155 Transfer from Smooth Muscle Cells to Endothelial Cells Induces Endothelial Injury and Promotes 
Atherosclerosis. Molecular therapy : the journal of the American Society of Gene Therapy, 25:1279-1294.

[145] Izarra A, Moscoso I, Levent E, Cañón S, Cerrada I, Díez-Juan A, et al. (2014). miR-133a enhances the protective capacity of cardiac progenitors cells after myocardial infarction. Stem Cell Reports, 3:10291042.

[146] Gao S, Wassler M, Zhang L, Li Y, Wang J, Zhang Y, et al. (2014). MicroRNA-133a regulates insulin-like growth factor-1 receptor expression and vascular smooth muscle cell proliferation in murine atherosclerosis. Atherosclerosis, 232:171-179.

[147] Song Y, Zhang C, Zhang J, Jiao Z, Dong N, Wang G, et al. (2019). Localized injection of miRNA-21enriched extracellular vesicles effectively restores cardiac function after myocardial infarction. Theranostics, 9:2346-2360.

[148] Qiao L, Hu S, Liu S, Zhang H, Ma H, Huang K, et al. (2019). microRNA-21-5p dysregulation in exosomes derived from heart failure patients impairs regenerative potential. The Journal of Clinical Investigation, 129:2237-2250.

[149] Mellows B, Mitchell R, Antonioli M, Kretz O, Chambers D, Zeuner MT, et al. (2017). Protein and Molecular Characterization of a Clinically Compliant Amniotic Fluid Stem Cell-Derived Extracellular Vesicle Fraction Capable of Accelerating Muscle Regeneration Through Enhancement of Angiogenesis. Stem Cells Dev, 26:1316-1333.

[150] Zavatti M, Beretti F, Casciaro F, Bertucci E, Maraldi T (2020). Comparison of the therapeutic effect of amniotic fluid stem cells and their exosomes on monoiodoacetate-induced animal model of osteoarthritis. Biofactors, 46:106-117.

[151] Snow ME, Keiver K (2007). Prenatal ethanol exposure disrupts the histological stages of fetal bone development. Bone, 41:181-187.

[152] Ni Q, Tan Y, Zhang X, Luo H, Deng Y, Magdalou J, et al. (2015). Prenatal ethanol exposure increases osteoarthritis susceptibility in female rat offspring by programming a low-functioning IGF-1 signaling pathway. Scientific Reports, 5:14711.

[153] Xiao H, Wen Y, Pan Z, Shangguan Y, Magdalou J, Wang H, et al. (2019). Nicotine exposure during pregnancy programs osteopenia in male offspring rats via $\alpha 4 \beta 2-n A C h R-p 300-A C E$ pathway. FASEB journal : official publication of the Federation of American Societies for Experimental Biology, 33:12972-12982.

[154] Deng Y, Cao H, Cu F, Xu D, Lei Y, Tan Y, et al. (2013). Nicotine-induced retardation of chondrogenesis through down-regulation of IGF-1 signaling pathway to inhibit matrix synthesis of growth plate chondrocytes in fetal rats. Toxicology and Applied Pharmacology, 269:25-33.

[155] GOLDSTEIN H (1981). FACTORS RELATED TO BIRTH WEIGHT AND PERINATAL MORTALITY. British Medical Bulletin, 37:259-264.

[156] Antoniades L, MacGregor AJ, Andrew T, Spector TD (2003). Association of birth weight with osteoporosis and osteoarthritis in adult twins. Rheumatology, 42:791-796.

[157] Jones G, Riley M, Dwyer T (1999). Maternal Smoking During Pregnancy, Growth, and Bone Mass in Prepubertal Children. Journal of Bone and Mineral Research, 14:146-151.

[158] Himmelreich M, Lutke CJ, Hargrove ET. 2020. The lay of the land: Fetal alcohol spectrum disorder (FASD) as a whole-body diagnosis. In The Routledge Handbook of Social Work and Addictive Behaviors. A.L. Begun, and M.M. Murray, editors. New York, NY: Routledge.

[159] Ryu AR, Kim DH, Kim E, Lee MY (2018). The Potential Roles of Extracellular Vesicles in Cigarette Smoke-Associated Diseases. Oxidative medicine and cellular longevity, 2018:4692081-4692081.

[160] Rahman MA, Patters BJ, Kodidela S, Kumar S (2020). Extracellular Vesicles: Intercellular Mediators in Alcohol-Induced Pathologies. Journal of Neuroimmune Pharmacology, 15:409-421.

[161] Todorova D, Simoncini S, Lacroix R, Sabatier F, Dignat-George F (2017). Extracellular Vesicles in Angiogenesis. Circulation research, 120:1658-1673.

[162] Ferreira E, Porter RM (2018). Harnessing extracellular vesicles to direct endochondral repair of large bone defects. Bone \& Joint Research, 7:263-273.

[163] Gerber H-P, Ferrara N (2000). Angiogenesis and Bone Growth. Trends in Cardiovascular Medicine, 10:223228.

[164] Hafsia N, Forien M, Renaudin F, Delacour D, Reboul P, Van Lent P, et al. (2020). Galectin 3 Deficiency Alters Chondrocyte Primary Cilium Formation and Exacerbates Cartilage Destruction via Mitochondrial Apoptosis. Int J Mol Sci, 21.

[165] Yang Q, Zhou Y, Cai P, Fu W, Wang J, Wei Q, et al. (2019). Up-regulated HIF-2alpha contributes to the Osteoarthritis development through mediating the primary cilia loss. Int Immunopharmacol, 75:105762.

[166] Farnum CE, Wilsman NJ (2011). Orientation of primary cilia of articular chondrocytes in threedimensional space. Anat Rec (Hoboken), 294:533-549.

[167] Wheway G, Nazlamova L, Hancock JT (2018). Signaling through the Primary Cilium. Front Cell Dev Biol, 6:8.

[168] Zhou J, Gao YH, Zhu BY, Shao JL, Ma HP, Xian CJ, et al. (2019). Sinusoidal Electromagnetic Fields Increase Peak Bone Mass in Rats by Activating Wnt10b/beta-Catenin in Primary Cilia of Osteoblasts. J Bone Miner Res, 34:1336-1351.

[169] Shi W, Gao Y, Wang Y, Zhou J, Wei Z, Ma X, et al. (2017). The flavonol glycoside icariin promotes bone formation in growing rats by activating the cAMP signaling pathway in primary cilia of osteoblasts. $\mathrm{J}$ Biol Chem, 292:20883-20896.

[170] Wang P, Tang C, Wu J, Yang Y, Yan Z, Liu X, et al. (2019). Pulsed electromagnetic fields regulate osteocyte apoptosis, RANKL/OPG expression, and its control of osteoclastogenesis depending on the presence of primary cilia. J Cell Physiol, 234:1058810601. 
[171] Martin-Guerrero E, Tirado-Cabrera I, Buendia I, Alonso V, Gortazar AR, Ardura JA (2020). Primary cilia mediate parathyroid hormone receptor type 1 osteogenic actions in osteocytes and osteoblasts via Gli activation. J Cell Physiol, 235:7356-7369.

[172] Lim J, Li X, Yuan X, Yang S, Han L, Yang S (2020). Primary cilia control cell alignment and patterning in bone development via ceramide-PKCzeta-betacatenin signaling. Commun Biol, 3:45.

[173] Xiao X, Tang JJ, Peng C, Wang Y, Fu L, Qiu ZP, et al. (2017). Cholesterol Modification of Smoothened Is Required for Hedgehog Signaling. Mol Cell, 66:154162 e110.

[174] Findakly S, Daggubati V, Garcia G, LaStella SA, Choudhury A, Tran C, et al. (2021). Sterol and oxysterol synthases near the ciliary base activate the Hedgehog pathway. J Cell Biol, 220.

[175] Nedelcu D, Liu J, Xu Y, Jao C, Salic A (2013). Oxysterol binding to the extracellular domain of Smoothened in Hedgehog signaling. Nat Chem Biol, 9:557-564.

[176] de Oliveira JC, Gomes RM, Miranda RA, Barella LF, Malta A, Martins IP, et al. (2016). Protein Restriction During the Last Third of Pregnancy Malprograms the Neuroendocrine Axes to Induce Metabolic Syndrome in Adult Male Rat Offspring. Endocrinology, 157:1799-1812.

[177] Li YX, Yang HT, Zdanowicz M, Sicklick JK, Qi Y, Camp TJ, et al. (2007). Fetal alcohol exposure impairs Hedgehog cholesterol modification and signaling. Lab Invest, 87:231-240.

[178] Wu S, De Luca F (2004). Role of cholesterol in the regulation of growth plate chondrogenesis and longitudinal bone growth. J Biol Chem, 279:46424647.

[179] Tseng AM, Mahnke AH, Wells AB, Salem NA, Allan AM, Roberts VH, et al. (2019). Maternal circulating miRNAs that predict infant FASD outcomes influence placental maturation. Life Sci Alliance, 2.

[180] Schock EN, Brugmann SA (2017). Discovery, Diagnosis, and Etiology of Craniofacial Ciliopathies. Cold Spring Harb Perspect Biol, 9.

[181] Suzuki A, Ogata K, Yoshioka H, Shim J, Wassif CA, Porter FD, et al. (2020). Disruption of Dhcr7 and Insig $1 / 2$ in cholesterol metabolism causes defects in bone formation and homeostasis through primary cilium formation. Bone Res, 8:1.

[182] Sun J, Shen H, Shao L, Teng X, Chen Y, Liu X, et al. (2020). HIF-1alpha overexpression in mesenchymal stem cell-derived exosomes mediates cardioprotection in myocardial infarction by enhanced angiogenesis. Stem Cell Res Ther, 11:373.

[183] Zhang W, Zhou X, Yao Q, Liu Y, Zhang H, Dong Z (2017). HIF-1-mediated production of exosomes during hypoxia is protective in renal tubular cells. Am J Physiol Renal Physiol, 313:F906-F913.

[184] Sriyanti R, Mose JC, Masrul M, Suharti N (2019). The Difference in Maternal Serum Hypoxia-Inducible Factors-1alpha Levels between Early Onset and LateOnset Preeclampsia. Open Access Maced J Med Sci,
7:2133-2137.

[185] Wu J, He Z, Gao Y, Zhang G, Huang X, Fang Q (2017). Placental NFE2L2 is discordantly activated in monochorionic twins with selective intrauterine growth restriction and possibly regulated by hypoxia. Free Radic Res, 51:351-359.

[186] Li HP, Chen X, Li MQ (2013). Gestational diabetes induces chronic hypoxia stress and excessive inflammatory response in murine placenta. Int J Clin Exp Pathol, 6:650-659.

[187] Zhao X, Yu FQ, Huang XJ, Xu BY, Li YL, Zhao XY, et al. (2018). Azithromycin influences airway remodeling in asthma via the PI3K/Akt/MTOR/HIF1alpha/VEGF pathway. J Biol Regul Homeost Agents, 32:1079-1088.

[188] Liu W, Zhang W, Wang T, Wu J, Zhong X, Gao K, et al. (2019). Obstructive sleep apnea syndrome promotes the progression of aortic dissection via a ROS- HIF-1alpha-MMPs associated pathway. Int J Biol Sci, 15:2774-2782.

[189] Zhang T, Ke W, Zhou X, Qian Y, Feng S, Wang R, et al. (2019). Human Neural Stem Cells Reinforce Hippocampal Synaptic Network and Rescue Cognitive Deficits in a Mouse Model of Alzheimer's Disease. Stem Cell Reports, 13:1022-1037.

[190] Yamasaki TR, Blurton-Jones M, Morrissette DA, Kitazawa M, Oddo S, LaFerla FM (2007). Neural stem cells improve memory in an inducible mouse model of neuronal loss. J Neurosci, 27:11925-11933.

[191] Wang Q, Matsumoto Y, Shindo T, Miyake K, Shindo A, Kawanishi M, et al. (2006). Neural stem cells transplantation in cortex in a mouse model of Alzheimer's disease. J Med Invest, 53:61-69.

[192] Zhang W, Gu GJ, Shen X, Zhang Q, Wang GM, Wang PJ (2015). Neural stem cell transplantation enhances mitochondrial biogenesis in a transgenic mouse model of Alzheimer's disease-like pathology. Neurobiol Aging, 36:1282-1292.

[193] Buss C, Entringer S, Swanson JM, Wadhwa PD (2012). The Role of Stress in Brain Development: The Gestational Environment's Long-Term Effects on the Brain. Cerebrum : the Dana forum on brain science, 2012:4-4.

[194] Gluckman PD, Hanson MA, Cooper C, Thornburg KL (2008). Effect of in utero and early-life conditions on adult health and disease. The New England journal of medicine, 359:61-73.

[195] Fang Y, Li H, Chang L, Song Y, Ma L, Lu L, et al. (2018). Prenatal stress induced gender-specific alterations of N-methyl-d-aspartate receptor subunit expression and response to $\mathrm{A} \beta$ in offspring hippocampal cells. Behavioural Brain Research, 336:182-190.

[196] Selkoe DJ, Hardy J (2016). The amyloid hypothesis of Alzheimer's disease at 25 years. EMBO Molecular Medicine, 8:595-608.

[197] Jafari Z, Okuma M, Karem H, Mehla J, Kolb BE, Mohajerani MH (2019). Prenatal noise stress aggravates cognitive decline and the onset and progression of beta amyloid pathology in a mouse 
model of Alzheimer's disease. Neurobiology of Aging, 77:66-86.

[198] Allen JL, Liu X, Weston D, Conrad K, Oberdörster G, Cory-Slechta DA (2014). Consequences of developmental exposure to concentrated ambient ultrafine particle air pollution combined with the adult paraquat and maneb model of the Parkinson's disease phenotype in male mice. Neurotoxicology, 41:80-88.

[199] Thiruchelvam M, Richfield EK, Baggs RB, Tank AW, Cory-Slechta DA (2000). The nigrostriatal dopaminergic system as a preferential target of repeated exposures to combined paraquat and maneb: implications for Parkinson's disease. J Neurosci, 20:9207-9214.

[200] Colle D, Santos DB, Naime AA, Gonçalves CL, Ghizoni H, Hort MA, et al. (2020). Early Postnatal Exposure to Paraquat and Maneb in Mice Increases Nigrostriatal Dopaminergic Susceptibility to a Rechallenge with the Same Pesticides at Adulthood: Implications for Parkinson's Disease. Neurotox Res, 37:210-226.

[201] Giguère N, Burke Nanni S, Trudeau L-E (2018). On Cell Loss and Selective Vulnerability of Neuronal Populations in Parkinson's Disease. Frontiers in Neurology, 9.

[202] Thiruchelvam M, Richfield EK, Goodman BM, Baggs RB, Cory-Slechta DA (2002). Developmental Exposure to the Pesticides Paraquat and Maneb and the Parkinson's Disease Phenotype. NeuroToxicology, 23:621-633.

[203] Bell MR (2018). Comparing Postnatal Development of Gonadal Hormones and Associated Social Behaviors in Rats, Mice, and Humans. Endocrinology, 159:2596-2613.

[204] Falker C, Hartmann A, Guett I, Dohler F, Altmeppen $\mathrm{H}$, Betzel C, et al. (2016). Exosomal cellular prion protein drives fibrillization of amyloid beta and counteracts amyloid beta-mediated neurotoxicity. J Neurochem, 137:88-100.

[205] Yu H, Sun T, An J, Wen L, Liu F, Bu Z, et al. (2020). Potential Roles of Exosomes in Parkinson's Disease: From Pathogenesis, Diagnosis, and Treatment to Prognosis. Frontiers in Cell and Developmental Biology, 8.

[206] Sardar Sinha M, Ansell-Schultz A, Civitelli L, Hildesjö C, Larsson M, Lannfelt L, et al. (2018). Alzheimer's disease pathology propagation by exosomes containing toxic amyloid-beta oligomers. Acta Neuropathol, 136:41-56.

[207] Rajendran L, Honsho M, Zahn TR, Keller P, Geiger KD, Verkade P, et al. (2006). Alzheimer's disease betaamyloid peptides are released in association with exosomes. Proc Natl Acad Sci U S A, 103:1117211177.

[208] Lord A, Kalimo H, Eckman C, Zhang XQ, Lannfelt L, Nilsson LN (2006). The Arctic Alzheimer mutation facilitates early intraneuronal Abeta aggregation and senile plaque formation in transgenic mice. Neurobiol Aging, 27:67-77.

[209] Perez-Gonzalez R, Gauthier SA, Kumar A, Levy E
(2012). The exosome secretory pathway transports amyloid precursor protein carboxyl-terminal fragments from the cell into the brain extracellular space. J Biol Chem, 287:43108-43115.

[210] Vingtdeux V, Hamdane M, Loyens A, Gelé P, Drobeck $\mathrm{H}$, Bégard S, et al. (2007). Alkalizing drugs induce accumulation of amyloid precursor protein byproducts in luminal vesicles of multivesicular bodies. J Biol Chem, 282:18197-18205.

[211] Lee S, Kim W, Li Z, Hall GF (2012). Accumulation of vesicle-associated human tau in distal dendrites drives degeneration and tau secretion in an in situ cellular tauopathy model. Int J Alzheimers Dis, 2012:172837.

[212] Saman S, Kim W, Raya M, Visnick Y, Miro S, Saman $\mathrm{S}$, et al. (2012). Exosome-associated tau is secreted in tauopathy models and is selectively phosphorylated in cerebrospinal fluid in early Alzheimer disease. J Biol Chem, 287:3842-3849.

[213] Russo I, Bubacco L, Greggio E (2012). Exosomesassociated neurodegeneration and progression of Parkinson's disease. American journal of neurodegenerative disease, 1:217-225.

[214] Emmanouilidou E, Melachroinou K, Roumeliotis T, Garbis SD, Ntzouni M, Margaritis LH, et al. (2010). Cell-produced alpha-synuclein is secreted in a calcium-dependent manner by exosomes and impacts neuronal survival. J Neurosci, 30:6838-6851.

[215] Stefanis L (2012). $\alpha$-Synuclein in Parkinson's disease. Cold Spring Harbor perspectives in medicine, 2:a009399-a009399.

[216] Chang C, Lang H, Geng N, Wang J, Li N, Wang X (2013). Exosomes of BV-2 cells induced by alphasynuclein: Important mediator of neurodegeneration in PD. Neuroscience Letters, 548:190-195.

[217] Crews L, Mizuno H, Desplats P, Rockenstein E, Adame A, Patrick C, et al. (2008). $\alpha$-Synuclein Alters Notch-1 Expression and Neurogenesis in Mouse Embryonic Stem Cells and in the Hippocampus of Transgenic Mice. The Journal of Neuroscience, 28:4250-4260.

[218] Lehmann SM, Krüger C, Park B, Derkow K, Rosenberger K, Baumgart J, et al. (2012). An unconventional role for miRNA: let-7 activates Tolllike receptor 7 and causes neurodegeneration. Nat Neurosci, 15:827-835.

[219] Fabbri M, Paone A, Calore F, Galli R, Gaudio E, Santhanam R, et al. (2012). MicroRNAs bind to Tolllike receptors to induce prometastatic inflammatory response. Proc Natl Acad Sci U S A, 109:E2110-2116.

[220] Siegel RL, Miller KD, Jemal A (2020). Cancer statistics, 2020. CA: A Cancer Journal for Clinicians, 70:7-30.

[221] Cullen JM, Breen M. 2016. An Overview of Molecular Cancer Pathogenesis, Prognosis, and Diagnosis. In Tumors in Domestic Animals. 1-26.

[222] Azmi AS, Bao B, Sarkar FH (2013). Exosomes in cancer development, metastasis, and drug resistance: a comprehensive review. Cancer and Metastasis Reviews, 32:623-642.

[223] Scotting PJ, Walker DA, Perilongo G (2005). 
Childhood solid tumours: a developmental disorder. Nature Reviews Cancer, 5:481-488.

[224] Bellacosa A (2013). Developmental disease and cancer: biological and clinical overlaps. American journal of medical genetics. Part A, 161A:2788-2796.

[225] Cruz L, Romero JAA, Iglesia RP, Lopes MH (2018). Extracellular Vesicles: Decoding a New Language for Cellular Communication in Early Embryonic Development. Frontiers in cell and developmental biology, 6:94-94.

[226] Burd L, Peterson L, Kobrinsky N (2014). Fetal alcohol spectrum disorders and childhood cancer: A concise review of case reports and future research considerations. Pediatric Blood \& Cancer, 61:768-770.

[227] Ohira M, Morohashi A, Inuzuka H, Shishikura T, Kawamoto T, Kageyama H, et al. (2003). Expression profiling and characterization of 4200 genes cloned from primary neuroblastomas: identification of 305 genes differentially expressed between favorable and unfavorable subsets. Oncogene, 22:5525-5536.

[228] Smith SM, Garic A, Flentke GR, Berres ME (2014). Neural crest development in fetal alcohol syndrome. Birth defects research. Part C, Embryo today : reviews, 102:210-220.

[229] Tavanasefat H, Li F, Koyano K, Gourtani BK, Marty V, Mulpuri Y, et al. (2020). Molecular consequences of fetal alcohol exposure on amniotic exosomal miRNAs with functional implications for stem cell potency and differentiation. PLOS ONE, 15:e0242276.

[230] Mukherjee S, Cabrera MA, Boyadjieva NI, Berger G, Rousseau B, Sarkar DK (2020). Alcohol Increases Exosome Release from Microglia to Promote Complement C1q-Induced Cellular Death of Proopiomelanocortin Neurons in the Hypothalamus in a Rat Model of Fetal Alcohol Spectrum Disorders. The Journal of Neuroscience, 40:7965-7979.

[231] Khanh VC, Yamashita T, Ohneda K, Tokunaga C, Kato $\mathrm{H}$, Osaka M, et al. (2020). Rejuvenation of mesenchymal stem cells by extracellular vesicles inhibits the elevation of reactive oxygen species. Scientific Reports, 10:17315.

[232] Hoover RN, Hyer M, Pfeiffer RM, Adam E, Bond B, Cheville AL, et al. (2011). Adverse Health Outcomes in Women Exposed In Utero to Diethylstilbestrol. New England Journal of Medicine, 365:1304-1314.

[233] Singh NP, Abbas IK, Menard M, Singh UP, Zhang J, Nagarkatti P, et al. (2015). Exposure to diethylstilbestrol during pregnancy modulates microRNA expression profile in mothers and fetuses reflecting oncogenic and immunological changes. Molecular pharmacology, 87:842-854.

[234] Liu T, Zhang Q, Zhang J, Li C, Miao Y-R, Lei Q, et al. (2018). EVmiRNA: a database of miRNA profiling in extracellular vesicles. Nucleic Acids Research, 47:D89-D93.

[235] Jazbutyte V, Thum T (2010). MicroRNA-21: from cancer to cardiovascular disease. Curr Drug Targets, 11:926-935.

[236] Mateescu B, Batista L, Cardon M, Gruosso T, de Feraudy Y, Mariani O, et al. (2011). miR-141 and
miR-200a act on ovarian tumorigenesis by controlling oxidative stress response. Nature Medicine, 17:16271635.

[237] Corthay A (2014). Does the immune system naturally protect against cancer? Frontiers in immunology, 5:197-197.

[238] Ribatti D (2017). The concept of immune surveillance against tumors. The first theories. Oncotarget, 8:71757180 .

[239] Johnson S, Knight R, Marmer DJ, Steele RW (1981). Immune Deficiency in Fetal Alcohol Syndrome. Pediatric Research, 15:908-911.

[240] Weinberg J, Jerrells TR (1991). Suppression of Immune Responsiveness: Sex Differences in Prenatal Ethanol Effects. Alcoholism: Clinical and Experimental Research, 15:525-531.

[241] Giberson PK, Weinberg J (1995). Effects of prenatal ethanol exposure and stress in adulthood on lymphocyte populations in rats. Alcohol Clin Exp Res, 19:1286-1294.

[242] Eken C, Gasser O, Zenhaeusern G, Oehri I, Hess C, Schifferli JA (2008). Polymorphonuclear NeutrophilDerived Ectosomes Interfere with the Maturation of Monocyte-Derived Dendritic Cells. The Journal of Immunology, 180:817-824.

[243] Pang X-L, Wang Z-G, Liu L, Feng Y-H, Wang J-X, Xie $\mathrm{H}-\mathrm{C}$, et al. (2019). Immature dendritic cells derived exosomes promotes immune tolerance by regulating $\mathrm{T}$ cell differentiation in renal transplantation. Aging, 11:8911-8924.

[244] Reis M, Mavin E, Nicholson L, Green K, Dickinson AM, Wang X-n (2018). Mesenchymal Stromal CellDerived Extracellular Vesicles Attenuate Dendritic Cell Maturation and Function. Frontiers in Immunology, 9.

[245] Song N, Zhang T, Xu X, Lu Z, Yu X, Fang Y, et al. (2018). miR-21 Protects Against Ischemia/Reperfusion-Induced Acute Kidney Injury by Preventing Epithelial Cell Apoptosis and Inhibiting Dendritic Cell Maturation. Frontiers in Physiology, 9.

[246] Cañas JA, Sastre B, Mazzeo C, Fernández-Nieto M, Rodrigo-Muñoz JM, González-Guerra A, et al. (2017). Exosomes from eosinophils autoregulate and promote eosinophil functions. Journal of Leukocyte Biology, 101:1191-1199.

[247] Robbins PD, Morelli AE (2014). Regulation of immune responses by extracellular vesicles. Nature Reviews Immunology, 14:195-208.

[248] Kim H, Lee MJ, Bae E-H, Ryu JS, Kaur G, Kim HJ, et al. (2020). Comprehensive Molecular Profiles of Functionally Effective MSC-Derived Extracellular Vesicles in Immunomodulation. Molecular Therapy, 28:1628-1644.

[249] Barnes BJ, Somerville CC (2020). Modulating Cytokine Production via Select Packaging and Secretion From Extracellular Vesicles. Frontiers in Immunology, 11.

[250] Yang Y, Boza-Serrano A, Dunning CJR, Clausen BH, Lambertsen KL, Deierborg T (2018). Inflammation leads to distinct populations of extracellular vesicles 
from microglia. Journal of Neuroinflammation, 15:168.

[251] Ng SP, Silverstone AE, Lai Z-W, Zelikoff JT (2005). Effects of Prenatal Exposure to Cigarette Smoke on Offspring Tumor Susceptibility and Associated Immune Mechanisms. Toxicological Sciences, 89:135-144.

[252] Cheemarla NR, Uche IK, McBride K, Naidu S, Guerrero-Plata A (2019). In utero tobacco smoke exposure alters lung inflammation, viral clearance, and CD8+ T-cell responses in neonatal mice infected with respiratory syncytial virus. American Journal of Physiology-Lung Cellular and Molecular Physiology, 317:L212-L221.

[253] Chen L, Huang H, Zhang W, Ding F, Fan Z, Zeng Z
(2019). Exosomes Derived From T Regulatory Cells Suppress CD8+ Cytotoxic T Lymphocyte Proliferation and Prolong Liver Allograft Survival. Medical science monitor : international medical journal of experimental and clinical research, 25:4877-4884.

[254] Farber HJ, Groner J, Walley S, Nelson K (2015). Protecting Children From Tobacco, Nicotine, and Tobacco Smoke. Pediatrics, 136:e1439-e1467.

[255] 2018. Secondhand Smoke and Cancer. NIH National Cancer Institute.

[256] Society AAC. 2020. Health Risks of Secondhand Smoke. ACS American Cancer Society.

[257] Besaratinia A, Pfeifer GP (2008). Second-hand smoke and human lung cancer. The Lancet Oncology, 9:657666. 